\title{
Fondos fotográficos del Instituto Valencia de Don Juan. Los negativos de Adela Crooke
}

\author{
Juan Miguel SÁNCHEZ VIGIL \\ Departamento de Biblioteconomía y Documentación \\ Facultad de Ciencias de la Documentación \\ Universidad Complutense de Madrid \\ jmvigil@ucm.es \\ María OLIVERA ZALDUA \\ Departamento de Biblioteconomía y Documentación \\ Facultad de Ciencias de la Documentación \\ Universidad Complutense de Madrid \\ molivera@ucm.es
}

\begin{abstract}
RESUMEN
Desde el último tercio del siglo XIX fue habitual la práctica de la fotografía amateur entre los intelectuales, con aportaciones de gran interés reconocidas por los investigadores. Entre los fondos del Instituto Valencia de Don Juan (Madrid) se conserva una colección de 276 negativos realizados entre 1893 y 1902 por Adela Crooke, condesa de Valencia de Don Juan y esposa de Guillermo de Osma Scull, de excepcional importancia por su contenido, con una temática diversa sobre caza, tauromaquia, deportes, animales, milicia, familia real y vistas de ciudades, especialmente Madrid. Es objeto de este trabajo poner en valor el fondo, analizar documentalmente los originales de Crooke, contextualizarlos en el conjunto de la institución, y reivindicar el papel de la mujer en la fotografía española.
\end{abstract}

Palabras clave: Adela Crooke, colecciones fotográficas, fotografía, Historia de la fotografía española, Instituto Valencia de Don Juan, negativos.

\section{The photographic collections of the Instituto Valencia de Don Juan. The negatives of Adela Crooke}

\begin{abstract}
Ever since the last third of the $19^{\text {th }}$ century, intellectuals have frequently been amateur photographers and they provided some very interesting work that has been recognized by researchers and scholars. The Instituto Valencia de Don Juan (Madrid) possesses a collection of 276 negatives shot between 1893 and 1902 by Adela Crooke, the Countess of Valencia de Don Juan and wife of Guillermo de Osma Scull. These negatives are of exceptional importance due to their content, covering highly diversified subject matter, including hunting, bullfighting, sports, animals, the militia, the royal family and visits to different cities, especially Madrid. The purpose of this study is to highlight the value of the collection, analyze and document Crooke's originals in relation with the context of the institution and bring to light the role of women in Spanish photography.
\end{abstract}

Keywords: Adela Crooke, photographic collections, photography, History of Spanish photography, Instituto Valencia de Don Juan, negatives. 


\section{INTRODUCCIÓN}

El término amateur se ha utilizado desde finales del siglo XIX para referirse a los aficionados a la fotografía, grupo conformado por intelectuales, políticos, aristócratas y profesionales liberales relacionados con el arte, la óptica, la química, la medicina, la moda, el excursionismo o la arqueología (Sánchez Vigil, 2013: 103). La práctica de la fotografía amateur se popularizó con la fundación de Kodak por George Eastman en 1888, y con la comercialización de nuevas cámaras de pequeño formato y carretes en papel que sustituyeron paulatinamente a las placas de vidrio. Una de las primeras definiciones del concepto amateur fue publicada por el historiador de la fotografía Giovanni Muffone (1914: 7): “Al gran número de los aficionados se ha añadido estos últimos años un nuevo ser; género anfibio entre el pintor, el viajero impresionista y el holgazán: me refiero al aficionado fotógrafo".

La mayoría de los amateurs fueron hombres, por lo que el estudio que aquí realizamos sobre los negativos de Adela Crooke, conservados en el Instituto Valencia de Don Juan (en adelante IVDJ), cobra especial interés dada la escasa práctica de la fotografía entre las mujeres, a las que Mónica Carabias (2000:22) atribuye un papel determinante como "colaboradoras y artífices en todos sus procesos de desarrollo". En esa misma línea se manifestó Mary Warner Marien (2002) al reivindicar la aportación de la mujer a la cultura de imagen.

Hemos de indicar que el acto fotográfico fue una manera de relacionarse, y al mismo tiempo una forma de mostrar y de reconocer el mundo. A finales del siglo XIX se crearon importantes asociaciones de aficionados, muchas de ellas con el término amateur en su denominación: Photo Club de París, Club der AmateurPhotographen de Viena (más tarde Wiener Kamera Klub), The Linked Ring Brotherhood (Londres), Amateur Photographic Association (Londres) o Society of Amateur Photographers de Nueva York. En España los grupos de aficionados no tuvieron como primer objetivo la fotografía, sino que se sirvieron de ella para difundir sus actividades, así la Real Sociedad Española de Historia Natural, Associaciò Catalanista d'Excursions Científiques, Centre Excursionista de Catalunya, Sociedad Alpina Peñalara o la Sociedad Española de Excursionistas. Las primeras agrupaciones específicamente fotográficas fueron la Sociedad Valenciana de Fotografía, Sociedad Fin de Siglo, la Sociedad ArtísticoFotográfica, y la Sociedad Fotográfica de Madrid creada en 1899 (Martín López, 2004; Sánchez Vigil, 2001).

Los amateurs no solo practicaron la fotografía sino que investigaron y teorizaron sobre ella, como indicó el periodista Francisco Delgado en 1904: "Los aficionados, los que no tomaron la fotografía como medio de vivir, ni redujeron su actividad a la reproducción de los rasgos fisonómicos, han sido los verdaderos iniciadores del arte fotográfico". El doctor Baltasar Hernández Briz (1907), miembro de la Real Sociedad Fotográfica de Madrid, estableció una clasificación en tres modelos en la revista Graphos Ilustrado: científica o de investigación, documental o histórica, y artística (Hernández, 1907). 
El estudio de fondos similares al que aquí se analiza, con fotografías tomadas por intelectuales o personajes de las clases sociales elevadas no es habitual, y aun menos con una mujer como autora. Entre las referencias citaremos la tesis doctoral sobre la colección fotográfica del músico Joaquín Turina (Olivera, 2010), o los libros sobre Ramón y Cajal (Romero, 1984) y Clementina Hawarden (Carabias, 2000).

El objeto de estudio de este trabajo es el conjunto de placas fotográficas en vidrio que se conservan en el IVDJ, relacionadas con la actividad cotidiana de la familia Osma-Crooke. Es objetivo específico aportar información sobre dichas fotografías, sobre la aportación de Adela Crooke como aficionada, y sobre los temas específicos que se muestran.

La metodología seguida ha sido: revisión bibliográfica sobre el tema a estudiar, inventariado de los negativos de vidrio y tratamiento documental de los mismos. Para ello se han realizado dos actuaciones de carácter técnico y analítico, en la primera se reprodujeron todos los negativos en un tablero de luz, generando dos carpetas con documentos digitales: la primera con imágenes en negativo (bruto) y la segunda con las fotos en positivo (para consulta, identificación y publicación). Para el análisis de contenido se diseñó una base de datos con los campos necesarios: Título, Autor, Descripción, Fecha, Lugar, Descriptores (Onomásticos, Geográficos, Cronológicos y de Materia), mas un campo de Notas. No se consideró necesario el campo con datos técnicos ya que todos los negativos tienen las mismas características y formatos: gelatinobromuros de plata en formato $4,5 \times 6 \mathrm{~cm}$.

Los datos obtenidos han sido procesados, contrastados y en su caso completados, con el fin de ponerla en valor, generando un listado de términos generales sobre los contenidos. Entre las fotografías analizadas se han seleccionado como ilustraciones al texto aquellas que se han considerado más convenientes, teniendo como criterios la relevancia y calidad de la imagen. Se completa el estudio con un anexo en el que se describen todos los negativos realizados por Adela Crooke.

\section{LA COLECCIÓN FOTOGRÁFICA DEL INSTITUTO VALENCIA DE DON JUAN}

La colección fotográfica del IVDJ, inventariada en parte por Ángeles Lázaro Martínez y María de los Ángeles Santos Quer, suma más de 10.000 documentos (Partearroyo, 2007), originales en soporte vidrio, papel y metal de diversos formatos, entre ellos 16 daguerrotipos y un ambrotipo. Lázaro Martínez elaboró el Inventario de álbumes fotográficos (2002) y la Guía-inventario de retratos fotográficos (2003), registrando en el primero 12 álbumes, seis de ellos con retratos de la familia de los condes y personalidades del siglo XIX, y otros tantos (7 a 12) con el título Los viajes de Adelín (Tabla 1). 
Tabla 1. Álbumes y número de copias

\begin{tabular}{lr} 
Álbum & Copias \\
\hline $1-3$ & 565 \\
4 & 135 \\
5 & 28 \\
6 & 126 \\
7 & 125 \\
8 & 167 \\
9 & 114 \\
10 & 165 \\
11 & 282 \\
12 & 259 \\
& \\
\hline Total & 1866
\end{tabular}

Fuente: elaboración propia

Los álbumes de viaje son de formato $28 \times 35 \mathrm{~cm}$, con la mayoría de las fotos en $6 \times 9 \mathrm{~cm}$. En todos ellos hay algunas copias en gran formato (albúminas de 20x25 $\mathrm{cm}$ ) de monumentos y vistas de excepcional calidad, adquiridas probablemente en los estudios o establecimientos comerciales de fotógrafos de prestigio, aspecto que incide en el interés de Crooke por la fotografía. La excepción es el álbum número 12 , cuyas medidas son $15 \times 26 \mathrm{~cm}$ y solo contiene positivos de $4 \times 5 \mathrm{~cm}$, precisamente las que se corresponden con los negativos que estudiamos.

Los viajes de Adelín. Contenidos de los álbumes

Álbum 6 (Año 1888)

Ciudades: Biarritz, Lucerna, Villa d'Este, Milán, Venecia, Viena

Contiene además fotos del lago de Como y Cernobbio

Álbum 7 (1888)

Ciudades: París, Havre, Barcelona, Londres

Contiene además fotos de Toulouse, Exposición Universal de Barcelona (2), Biblioteca Nacional de Madrid (1) y Paisaje sin identificar (1).

Álbum 8 (1889)

Ciudades: Biarritz, Madrid, Sevilla, Tánger, Granada, Córdoba, Ouchy, París

Álbum 9 (1890)

Ciudades: París, Saint Moritz y Schinznach

Contiene además fotos de personajes en el interior de un palacio

Álbum 10 (1891-1892)

Ciudades: Saint Moritz, Schinznach, Muhlen, Berna, Ouchy, Ginebra 
Álbum 11 (1892)

Ciudades: Niza, Roma, Nápoles; Pompeya, Palermo, Taormina, Corfú, Atenas, Esmirna, Estambul, Scutari, Belgrado, Brusa.

Contiene además fotos de: Gibraltar, Villa Cyrnos en Cap Martín, Menton, Liborio. Originales de C. Berggren, Sebah Joaillier y Gulmez freres. Dibujo de A. Caula del barco Thistle de la emperatriz Eugenia de Montijo. Álbum 12 (1893-1902)

Ciudades: Madrid, París, Segovia, Toledo

Contiene además fotos de Loyola, Guernica, castillos de Arteaga y Butrón, Zarautz, Bilbao, Dieppe y Newhaven.

La Guía-inventario de retratos fotográficos, elaborada por Lázaro Martínez en 2003, consta de 473 retratos, una parte de ellos sueltos y conservados en una arqueta del museo. Estas fotos se distribuyen en dos grandes grupos: retratos y fiestas populares, con una magnífica colección de baile de disfraces.

1. Familia Guillermo de Osma: 88

Formato carte de visite

2. Familia del Conde, Casa Real, Casa de Alba y personajes sin identificar: 81

Formato cabinet

3. Retratos varios: 70

Formatos medios

4. Baile de trajes de carnaval: 37

Palacio de los Condes de Fernán Núñez, 25 de febrero de 1884.

Tomados por Edg. Debas, Barcia y Viet, Hebert, Borke y Ferriz)

5. Carnaval: 12

21 de febrero de 1887. Tomados por Edg. Debas, Borke y Ferriz

6. Retratos en el despacho de Guillermo de Osma: 171

Formatos varios: enmarcados y colgados

7. Retratos en la biblioteca del Instituto: 14

Formatos varios: enmarcados y colgados

María Ángeles Santos Quer $(2004,2009)$ ha realizado un completo estudio sobre las fotos de Laurent ${ }^{1}$ y Alinari ${ }^{2}$, dos de los más prestigiosos profesionales de

${ }^{1}$ Jean Laurent (Nevers, 1816-Madrid, 1886) abrió estudio en 1857 en la Carrera de San Jerónimo de Madrid. Viajó impresionando negativos d monumentos y obras de arte. Creó un archivo que comercializó mediante catálogos. En 1874 amplió la empresa junto a su hijastra Catalina Melina Dosch, y sus sucesores ampliaron la colección: Lacoste, Roig, Portugal y Ruiz Vernacci. (Sánchez Vigil, 2007: 338)

${ }^{2}$ La actividad de los hermanos Leopoldo, Romualdo y Giuseppe Alinari comenzó en Florencia en 1856 con la editorial Fratelli Alinari, especializada en la reproducción fotográfica de obras de arte. En 1865 publicaron el primer catálogo de imágenes de Florencia y la Toscana. Vittorio Alinari, hijo de Leopoldo, relanzó la editorial a finales de 
la segunda mitad del siglo XIX, en la Guía-inventario de la colección fotográfica del Instituto de Valencia de Don Juan, donde indica las pautas de su recuperación y conservación. Los temas son diversos, siempre relacionados con el arte y la cultura popular: etnografía, costumbres, arquitectura y especialmente la reproducción de obras de arte: pintura, escultura, tapices, encuadernaciones, bordados, armaduras, etc. El primer inventario de Santos (2004), se compone de cerca de 500 imágenes, clasificadas en siete series: 1. Alinari, 2. Laurent (Figura 1), 3. Sucesores de Laurent y otros, 4. Instituto Valencia de Don Juan, 5. Privada, 6. Miscelánea y 7. Foto contemporánea. Además de las fotos de la familia y del edificio, las materias son arquitectura, monumentos, pintura, escultura, tapices, armería, miniaturas, dibujos, grabados, encuadernaciones y reproducciones de arte. En el segundo inventario (2009) añadió 800 positivos realizados, entre otros autores de prestigio, por Laurent (725 fotos), Grimaud, Busato y Bonara. A las imágenes inventariadas por Lázaro Martínez y Santos Quer hay que añadir originales dispersos en archivadores junto a la documentación de piezas del museo, desde albúminas del siglo XIX hasta diapositivas en gran formato $(13 \times 18 \mathrm{~cm})$ realizadas por especialitas como Oronoz, fotos empleadas para documentar las piezas.

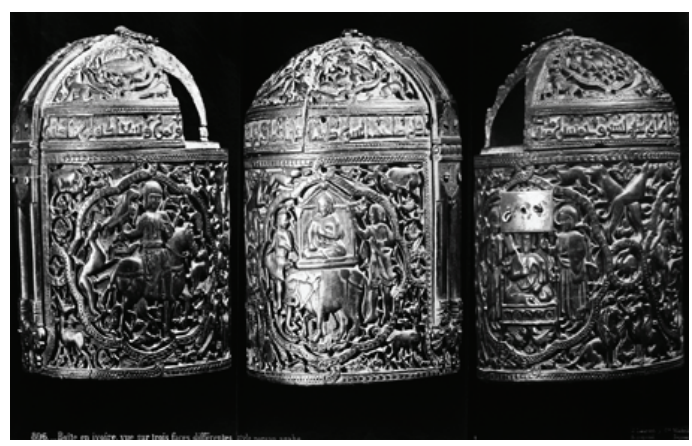

Figura 1. Bote persa de marfil. Fotografía de Laurent y Cía.

siglo y cofundó la Sociedad Fotográfica Italiana. La colección Alinari, con más de 100.000 negativos históricos, es base de más de 6.000 libros de arte (Sánchez Vigil, 2007: 25). 
Por lo que respecta a los daguerrotipos ${ }^{3}$ y al ambrotipo, se trata de una importantísima colección de retratos compuesta por 17 piezas estuchadas, en buen estado de conservación a excepción de dos, con daños en la imagen. En cuanto a la autoría, se conoce el nombre de ocho fotógrafos o estudios: cinco proceden de la Branv's Gallery de Nueva York, uno del estudio de M. Vallette en La Habana, otro de la galería de M. Kilburn en Londres, y el octavo producido por Pease y Cía. en Lima. El inglés William Edward Kilburn (1818-1891) tuvo estudio en la calle Regent de Londres desde 1846, donde retrató a la familia real británica; fue galardonado con una medalla en la Exposición Internacional de 1851 y se conservan 66 daguerrotipos en la National Portrait Gallery. El neoyorquino Benjamín Pease (1822-1888) llego a Lima en 1852 y trabajó en el estudio de Arthur Ferry antes de instalarse en la calle Plateros de San Pedro, anunciándose como Gabinete de pinturas. El francés Marc Vallette (1844-1852) se estableció en el número 86 de la calle del Obispo de La Habana en abril de 1843, y más tarde en el número 33, donde comercializó "aparatos enderezadores" fabricados por Richebourg, operador de Daguerre. En 1849 se anunciaba como "el más antiguo en La Habana" y 1852 se trasladó a Ciudad de México.

Relación de daguerrotipos (y ambrotipo) ${ }^{4}$

1. 325F. Branv's Gallery (205-350 Broadway Nueva York). Nombre del autor estampado en el terciopelo. Retrato de niña ovalado. Dañado. Marco rectangular. $9,5 \times 8,5 \mathrm{~cm}$.

2. 326F. Branv's Gallery (205 a 350 Broadway New York). Nombre del autor estampado en el terciopelo. Retrato de niña. Imagen dañada. 9,5 x $12 \mathrm{~cm}$.

3. 327F. Branv's Gallery (205 a 350 Broadway New York). Nombre del autor estampado en el terciopelo. Retrato de niña. Marco ovalado. 9,5 x $12 \mathrm{~cm}$.

4. 328F. Branv's Gallery (205 a 350 Broadway New York). Nombre del autor estampado en el terciopelo. Retrato de niña. Marco ovalado. 9,5 x $12 \mathrm{~cm}$.

5. 329F. Branv's Gallery (205 a 350 Broadway New York). Nombre del autor estampado en el terciopelo. Retrato de niña, coloreado en la cara. 9,5 x 12 $\mathrm{cm}$.

${ }^{3}$ El daguerrotipo, creado por Louis J. Mandé Daguerre es una placa de cobre pulida y recubierta de plata. Se sensibilizaba con vapores de yodo para obtener yoduro de plata, después era expuestos a la luz y por último se aplicaba vapor de mercurio para hacer visible la imagen. Se generó una importante industria, ya que se presentaban en estuches de piel y terciopelo (Sánchez Vigil, 2007: 165). Los ambrotipos deben el nombre a James Ambroise Cutting. Tienen su origen en el procedimiento ideado a mediados del siglo XIX por J. R. Le Moyne mediante el que se obtenían originales directos sobre placa de cristal, que con un fondo oscuro realzaba la imagen y daba el efecto de un positivo. Su acabado era similar al de los daguerrotipos (Sánchez Vigil, 2007: 33)

${ }^{4}$ Se describen en el siguiente orden: Signatura, autor, datos técnicos, contenidos y formato 
6. 330. Desconocido. Retrato de señor con gorro, perfil derecho. Coloreado en rojo las mejillas. Marco interior ovalado. Dañado. 9,5 x $12 \mathrm{~cm}$.

7. 331F. M. Vallette (Havana (sic), calle del Obispo 33). Nombre del autor estampado en terciopelo interior. Marco ovalado. Retrato de señor ligeramente dañado. $9,5 \times 12 \mathrm{~cm}$.

8. 332F. Desconocido. Conde Valencia de Don Juan, h.1865. Coloreado en oro botonadura, cuello y mangas. Donativo del Conde de Albiz. Ventana con semicírculo. $9,5 \times 12 \mathrm{~cm}$.

9. 333F. M. Kilburn (234 Recent Street, Londres). Retrato de J. Crooke y Navarro. Coloreado. Marco interior rectangular con semicírculo superior. $9,5 \times 12 \mathrm{~cm}$.

10. 335F. Desconocido. Retrato de señora con libro en la mano derecha. Coloreados collar y adorno en la falda. Marco interior rectangular con adorno en curva. $9,5 \times 12 \mathrm{~cm}$.

11. 336F. Desconocido. Retrato de dos señoras sentadas con igual vestido. Marco interior rectangular con esquinas en hexágono. 12 x $15 \mathrm{~cm}$.

12. 337F. Desconocido. Retrato de señora. Dañado. Marco rectangular con interior en cenefa octogonal. $9,5 \times 8,5 \mathrm{~cm}$.

13. 338 F. Desconocido. Retrato de mujer. Marco ovalado. $9,5 \times 8,5 \mathrm{~cm}$.

14. 339F. Desconocido. Tía Teresa con su hijo Luis Galiano en brazos. Formato rectangular con bordes redondeados. 9,5 x $12 \mathrm{~cm}$.

15. 340F. Desconocido. Retrato de señora de frente (¿Tía Margarita?). Marco rectangular e interior hexagonal. $9,5 \times 12 \mathrm{~cm}$.

16. 342F. Pease y Ca. Retratistas (Lima, calle de Plateros 14). Nombre en el marco interior. Retrato de señora. Coloreados en oro el collar, los pendientes, la botonadura, y en rojo la cara y labios. Marco rectangular con bordes redondeados. $12 \times 15 \mathrm{~cm}$.

17. 334F. Ambrotipo. Desconocido. Retrato de niña coloreado en el rostro. Marco ovalado con formas octogonales. $9,5 \times 8,5 \mathrm{~cm}$.

\section{ADELA CROOKE Y LA FOTOGRAFÍA}

Nacida en Madrid el 20 de noviembre de 1883, Adela Crooke y Guzmán era hija de Juan Bautista Crooke y Navarro, conde de Valencia de Don Juan, diplomático, arqueólogo e investigador, a quien su pasión por el arte llevó a formar una gran colección que completó la de su esposa, Adela Guzmán, con piezas de artes decorativas: tapices, alfombras, tejidos, encajes o bordados. 


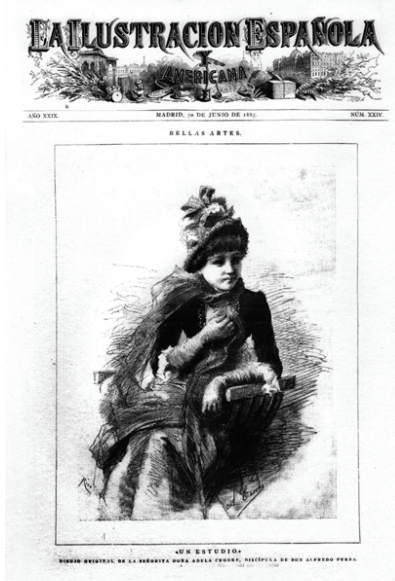

Figura 2. En el estudio. Ilustración de Adela Crooke en portada de La Ilustración Española y Americana, 30 de junio de 1885

Crooke fue una mujer culta, erudita, estudiosa del arte y de la historia, pintora, acuarelista, e ilustradora, discípula del artista Alfredo Perea ${ }^{5}$. El 30 de junio de 1885 se publicó en portada de La Ilustración Española y Americana uno de sus dibujos, titulado "Un estudio" (Figura 2), sobre el que escribió Eusebio Martínez de Velasco:

En la plana primera de este número reproducimos (fotografía de Laurent) el bello dibujo titulado Un Estudio, original de la distinguida Sra. $\mathrm{D}^{\mathrm{a}}$ Adela de Crooke; representa una linda joven, de viva mirada y halagüeña sonrisa, en actitud graciosa y a la par sencilla. La Sra. de Crooke, discípula aventajada de nuestro antiguo colaborador artístico D. Alfredo Perea, ha emprendido con seguros pasos el difícil camino del arle, $v$ esa interesante producción suya debe ser considerada como feliz augurio y testimonio indudable de aptitudes ventajosísimas. Pertenece la Srta. Crooke á raza de artistas, y nobleza obliga: es hija del Conde de Valencia de Don Juan, cuyos vastos conocimientos en Arqueología y en Bellas Artes, demostrados plenamente con la restauración de la Real Armería, le otorgan con justicia el doble titulo de hombre docto y delicado artista.

${ }^{5}$ Alfredo Perea Rojas (Madrid, 1839-1895). Pintor, dibujante e ilustrador cuya obra fue muy profusa. Colaboró como ilustrador en las principales revistas de la segunda mitad tercio del siglo XIX, entre ellas El Museo Universal, La Ilustración de Madrid o La Ilustración Española y Americana. 
El 1 de mayo de 1888, con 25 años, contrajo matrimonio con Guillermo Joaquín de Osma y Scull (La Habana, 1853-La Negresse, Francia, 1922). Durante la luna de miel reveló su interés por la fotografía al documentar el viaje de novios con una cámara "Facile" de 6x9 cm (Figura 3), fabricada por la empresa británica Miall. El aparato se conserva en el Instituto, es de madera barnizada, con foco fijo y visor lateral, y la inscripción: "PAT JAN. 2.88". Frank Miall creó este modelo, conocido como "detective", en 1887-1888, junto con las placas de vidrio apropiadas. La comercializó el químico Jonathan Fallowfield y se realizaron varias versiones con distinta luminosidad. Su principal característica fue la rapidez de carga de las placas, y sus inconvenientes el volumen, el peso y el foco fijo.

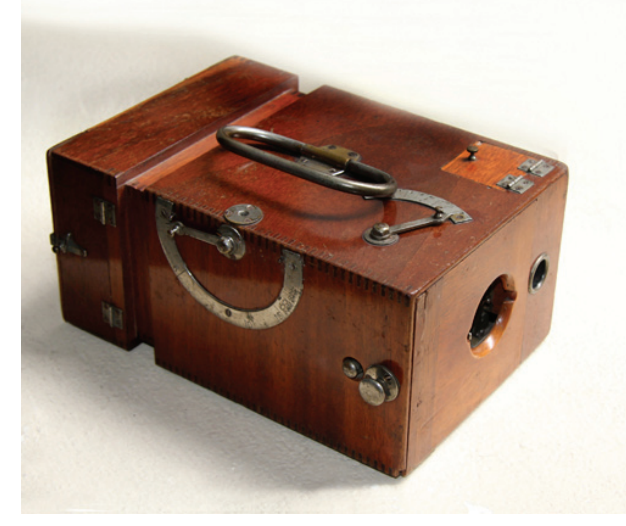

Figura 3. Cámara "Facile" de Miall utilizada por Adela Crooke. Instituto Valencia de Don Juan

En el diario que Adela Crooke escribió entre el 12 de abril y el 17 de julio de 1897, durante un viaje por Europa, hizo varias alusiones a la fotografía. La primera con motivo de la visita a la ganadería de Joaquín Murube en Tablada (Sevilla) el 17 de abril, donde conoció al toro Playero, que se dejaba acariciar y sobre el que escribió "El bicho se ha portado de un modo increíble, nos hemos montado encima y he hecho varios grupos (fotos) con él". Esa misma tarde Playero fue indultado en la corrida celebrada en La Maestranza, a la que también asistió Crooke ${ }^{6}$. Otra referencia concreta se encuentra en las notas del 6 de julio, donde comenta la visita a la mezquita de Mouradia (Argelia): "Fuimos al bazar a hacer fotografías y comprarnos persas, imitaciones de cachemire baratísimas".

${ }^{6}$ El toro Playero fue muy popular en la época porque se dejaba montar y acariciar por los cuidadores. Aunque en el campo no embestía y se dejaba montar y acariciar por sus cuidadores fue lidiado la tarde del 18 de abril de 1897 en La Maestranza, y el público pidió su indulto. Dos meses después, el 20 de junio, fue lidiado por segunda vez en la plaza de Lisboa, y nuevamente fue indultado y conducido al campo donde murió de viejo. 
La figura de Guillermo de Osma (Partearroyo, 2007), doctor en Arte por la Universidad de Oxford, es fundamental para entender la aportación de su esposa, Adela Crooke, a la fotografía. Son muchos los datos que constatan su afición, en especial la instalación de un estudio y gabinete en el torreón del palacio donde todavía se conserva en la ventana ojival el cristal rojo para proteger el material sensible a la luz. Por otra parte, la cámara conservada y la gran cantidad de originales, tanto los realizados por Crooke como los retratos de familia y las reproducciones de obras de arte, nos indican su interés por la materia (Figura 4). Además, la familia Osma conservó tres álbumes de cartes de visite, procedentes de la colección de Gaspar Osma Ramírez de Arellano y de su mujer Cecilia Luisa Scull Audouin, que se hallan en el Instituto de Estudios Riojanos y que han sido estudiados por Ignacio Gil-Díez Usandizaga (2013).

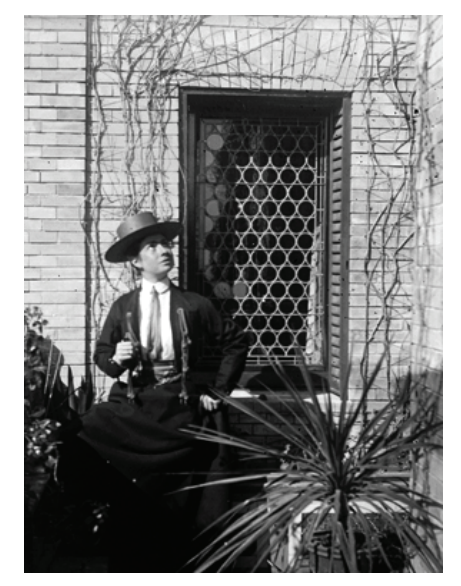

Figura 4. Adela Crooke en marzo de 1894

La unión de las dos colecciones de arte tras su matrimonio, junto con la herencia de Juan Bautista Crooke en 1904, conformó el excepcional conjunto que al crear el Instituto, en 1916, se abrió a la investigación y al estudio (Partearroyo, 2007: 121), gestionado después de la muerte de Osma por un Patronato ${ }^{7}$.

Adela Crooke falleció en París el 17 de enero de 1918 y, tras su muerte, el presidente de la Republica le concedió la medalla de la Reconnaissance Francaise. Fue sepultada en el cementerio de Saint Germain en Laye, localidad próxima a París muy popular por su castillo.

${ }^{7}$ Los componentes del primer Patronato fueron: Antonio Vives y Escudero (18591925), catedrático, arqueólogo y numismático; Miguel Asín Palacios (1871-1944), catedrático arabista; Julián Ribera (1858-1934) arabista; Antonio Maura y Montaner (18531925) jefe del Gobierno en 1903, 1907 y 1971; el duque de Alba Jacobo Stuart Fitz-James y Falcó (1878-1955), historiador de grandes colecciones artísticas; Acher M. Huntington (1870-1955), fundador de la Hispanic Society of America. 


\section{LOS NEGATIVOS DE VIDRIO}

El conjunto de negativos de vidrio se encuentra en el fondo denominado "Cajas Verdes" (fila 1, columna 4-Izq.), que se describe en su exterior como: "Foto (sic) antiguas curiosas sobre cristal. Abanicos. FRAGIL" (este apunte indica que en algún momento se guardaron abanicos en ella). Los negativos se conservan dentro de un estuche, en buen estado, y junto a ellos una placa de vidrio de $13 \times 18 \mathrm{~cm}$ en la que se reproducen cuatro retratos de personajes ilustres: Luis Lasso de la Vega, Pedro Lasso de la Vega (Conde de los Arcos), Mariana de Mendoza (Condesa de los Arcos) y María Pacheco y Aragón.

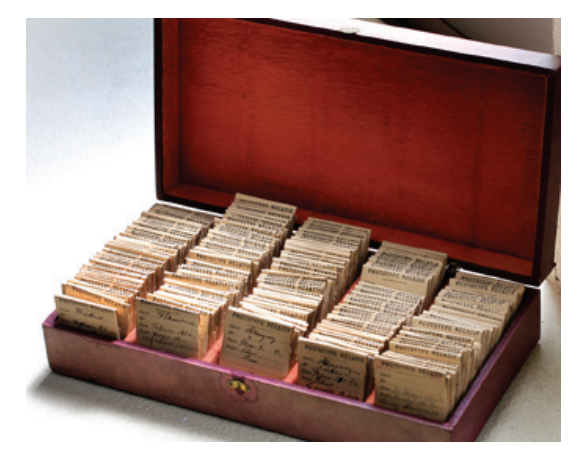

Figura 5. Estuche con los negativos de vidrio

El estuche es de madera, forrado en semipiel de color corinto, y con la inscripción "PHOTO-JUMELLE" estampada en oro en el exterior. Sus dimensiones son 15,5 cm de ancho, 30 de largo y 7,5 de alto. El interior de la tapa está forrado de terciopelo, y se divide en cinco espacios en los que se distribuyen los sobres con los negativos (Figura 5). Las notas en los sobres son manuscritas, siempre con la misma letra, y la mayoría con información sobre el tema. No guardan orden cronológico ni temático, y en la parte inferior de cada uno de los sobres está impresa la dirección del fabricante del material (Figura 6). 


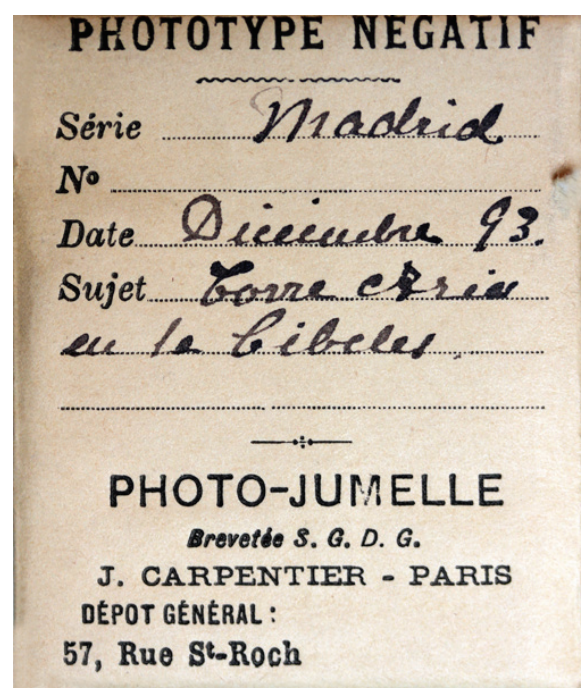

Figura 6. Sobre de negativos, $4 \times 5 \mathrm{~cm}$

La marca Jumelle (Gemelos) fue creada por la firma francesa Carpentier Photo, que fabricó la cámara del mismo nombre entre 1892 y 1910, caracterizada por dos lentes en forma de gemelos, una de las cuales hacía función de visor y la otra de objetivo. Disponía de un sistema automático de cambio de placas y permitía obtener doce fotografías consecutivas. Con una máquina similar a la descrita, Adela Crooke debió tomar las fotografías que analizamos.

\subsection{Análisis cuantitativo y cualitativo}

Los negativos son 276 en formato $4,5 \times 6 \mathrm{~cm}$, y se guardan en 211 sobres, ya que varios de ellos contienen dos originales (Tabla 2). Se corresponden con el álbum 12 (sig. 12F, 1893-1902) de los inventariados por Lázaro, con 259 fotografías de $4 \times 5 \mathrm{~cm}$, distribuidas en 34 páginas (el resto hasta 48 vacías), y que presenta como: "Vida social de los Fundadores. Asistencia a cacerías en La Flamenca, corridas de toros, Madrid: vistas de Fortuny 17; actos oficiales en torno al Palacio Real, etc." Este álbum contiene además un sobre de tamaño $15 \times 20 \mathrm{~cm}$ con 8 dibujos de Cherry (el perro de la familia), uno de ellos fechado el 7 de enero de 1900, más una lámina de J\&J Colman Limited con seis ellos de coleccionista. 
Tabla 2. Distribución de los originales en el estuche

\begin{tabular}{|c|c|c|c|c|c|}
\hline FILAS & 1 & 2 & 3 & 4 & 5 \\
\hline SOBRES & 48 & 46 & 39 & 36 & 43 \\
\hline NEGATIVOS & $1-49$ & $\begin{array}{c}50- \\
109\end{array}$ & $110-170$ & $171-218$ & $219-276$ \\
\hline
\end{tabular}

Fuente: elaboración propia

Las primeras fotos están fechadas en agosto de 1893 y se corresponden con el viaje realizado a Eastbourne (Inglaterra), durante la travesía del Canal de la Mancha. Las últimas llevan fecha del 21 de mayo de 1902 y fueron realizadas durante una revista militar en Madrid. Los periodos de toma son: agosto de 1893, mayo de 1895, 1898 y 1902. En esos años Guillermo de Osma tuvo una intensa actividad política como subsecretario de Hacienda y diputado a Cortes, antes de ser ministro con Antonio Maura (1903-1904 y 1907-1908).

La valoración en cuanto a su contenido presenta una colección de carácter documental obtenida en función de intereses privados que responde a la secuencia vital; es decir, como testigo de las vivencias. Hemos establecido nueve categorías temáticas (Tabla 3). El número de imágenes se reparte de manera desigual, destacando las fotografías de personajes (96), en su mayoría retratos de la familia Osma-Crooke, y las vistas de ciudades (56), en especial las de Madrid (Figura 7). La colección de retratos, además de numerosa, es importante para la identificación, pero también para estudios relacionados con la sociología, la cultura e incluso con el vestido. A este conjunto se suman los retratos de la Familia Real (Alfonso XIII, la infanta Isabel de Borbón, María Cristina de Habsburgo-Lorena, etc.) que hemos optado por incluir en un apartado específico, compuesto de 25 originales de los que 16 son del acto público de la Jura de Alfonso XIII en el Congreso de los Diputados.

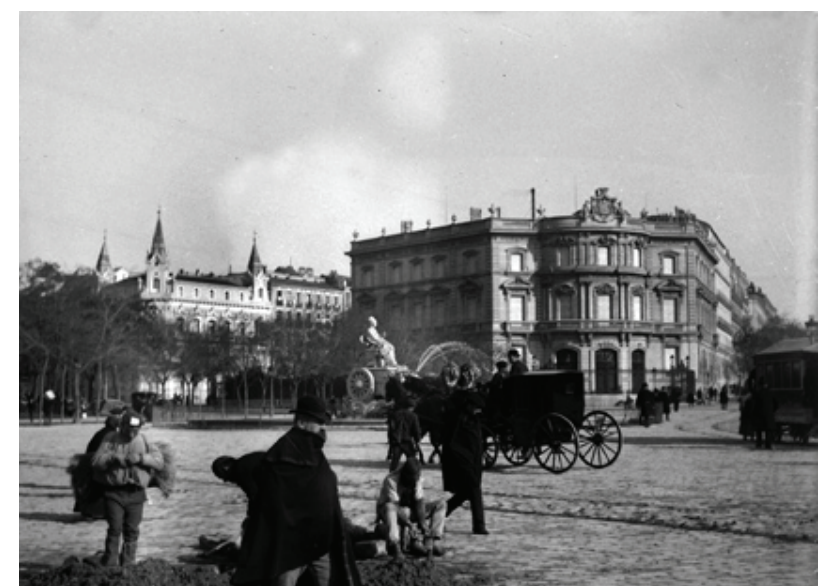

Figura 7. Madrid. Plaza de Cibeles, diciembre de 1893 
La colección de tauromaquia (Figura 8) también es amplia y diversa, con escenas de lidia, toros en el campo y capeas populares. Las más significativas se corresponden con la tradicional corrida de San Fernando en Aranjuez el 30 de mayo de 1894, en la que intervinieron los diestros Luis Mazzantini y Guerrita. Son también de gran interés las escenas de toros en el campo en los alrededores de Alcalá de Henares.

El grupo de fotos sobre caza (Figura 9) y deporte es interesante porque representa las actividades en su desarrollo, es decir con espontaneidad. Destacan las 8 imágenes de hípica y la veintena sobre caza en monte bajo con galgos. El conjunto sobre militares en actos oficiales (desfiles) es reducido, y el valor del grupo de transporte se halla en la diversidad de coches de caballos o carruajes, entre ellos los denominados break y mylord, completados con los de vapor y los tranvías.

En cuanto a las ciudades y paisajes, la media de fotografías es muy superior al resto, como también es significativo el número de negativos sobre animales (30), en especial los de caballos (18), que se completan con la colección de fotos de Cherry, el perro de la familia que fue enterrado en el jardín del palacete de la calle Fortuny.

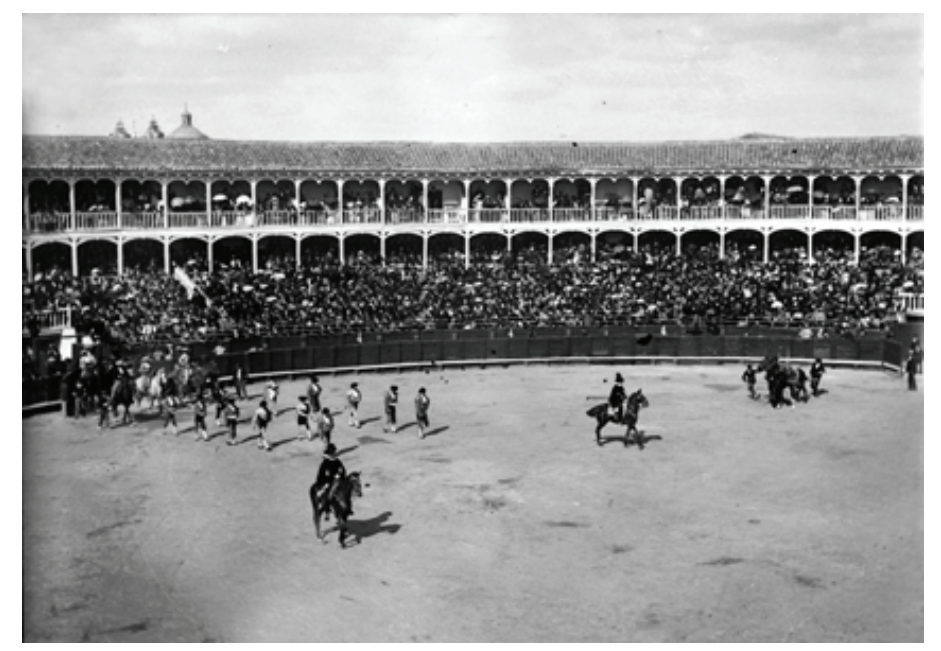

Figura 8. Corrida de toros en Aranjuez.

Paseíllo de Mazzantini y Guerrita, 30 de mayo de 1894 


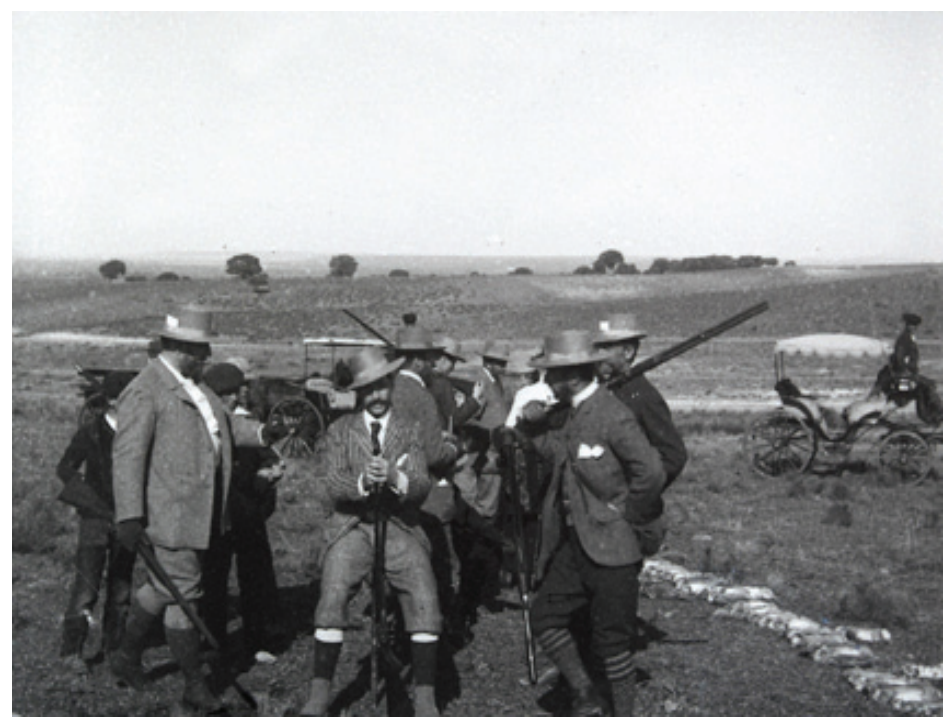

Figura 9. Cazadores en la finca La Flamenca de Aranjuez, febrero de 1894

Tabla 3. Contenidos

\begin{tabular}{|l|r|}
\hline \multicolumn{1}{|c|}{ TEMAS } & NEGATIVOS \\
\hline Animales & 30 \\
\hline Casa Real & 25 \\
\hline Caza & 20 \\
\hline Deportes & 11 \\
\hline Lugares & 56 \\
\hline Militares & 6 \\
\hline Personajes (familia y otros) & 96 \\
\hline Tauromaquia & 17 \\
\hline Transporte & 15 \\
\hline \multicolumn{2}{|r}{ TOTAL } \\
\hline
\end{tabular}

Fuente: elaboración propia

Las vistas de lugares (Tabla 4) corresponden en su mayoría a Madrid y a ciudades de los alrededores: La Granja, Aranjuez, Segovia o Toledo. Sobre Madrid son de especial interés las vistas del palacete de los Condes de Valencia de Don Juan, el Campo del Moro del Palacio Real, la plaza de Cibeles, el Paseo del Prado o la Carrera de San Jerónimo. En algunos de los retratos de militares pueden verse la calle de Alcalá y la Carrera de San Jerónimo con los comercios, las iglesias o las obras de pavimentación. Para el estudio de la historia local son de interés las fincas y parajes de recreo como Soto de la Ciudad en Alcalá de Henares, Romanillos en Boadilla del Monte (propiedad de la Casa de Alba) o La Flamenca en Aranjuez. Es 
también importante el grupo de vistas de Sevilla, con 10 originales (Figura 10), y las fotos de fuera de España.

Tabla 4. Vistas de Lugares

\begin{tabular}{|c|c|}
\hline LUGAR & FOTOS \\
\hline Aranjuez & 2 \\
\hline Boulogne & 1 \\
\hline Dave & 2 \\
\hline Eastbourne & 9 \\
\hline Folkestone & 1 \\
\hline La Granja & 3 \\
\hline Londres & 1 \\
\hline Madrid & 14 \\
\hline Oxford & 3 \\
\hline París & 3 \\
\hline Segovia & 2 \\
\hline Sevilla & 10 \\
\hline Toledo & 1 \\
\hline Villamiel & 2 \\
\hline Zuazo & 2 \\
\hline TOTAL & 56 \\
\hline & \\
\hline & \\
\hline & \\
\hline & \\
\hline
\end{tabular}

Fuente: elaboración propia

Por lo que se refiere a la calidad, se trata de un fondo de aficionado, con encuadres pulcros, sobre todo en las vistas generales, y una estética propia de las creaciones artísticas o creativas. Es curioso que tan solo 12 tomas sean verticales. La intención documental es también evidente, con el objeto de dejar constancia del hecho o del lugar. Señalaremos como características la espontaneidad y frescura, los sencillos y en ocasiones originales encuadres en las tomas de los animales (el perro Cherry) y la contextualización de los personajes en su ambiente, propio de la fotografía documental.

Más allá de las cuestiones formales, conviene advertir sobre un detalle poco o nada habitual entre los usuarios de la fotografía: la conservación de los negativos. Este aspecto delata un interés que trasciende la simple captación, ya que la posesión del negativo presuponía la posibilidad de obtener copias y por otra parte de justificar y reivindicar la autoría. 


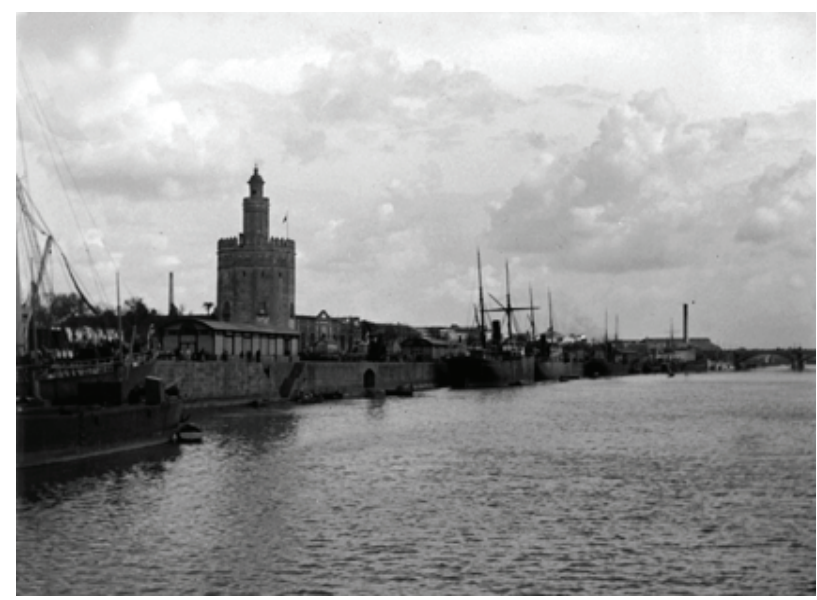

Figura 10. Sevilla. El Guadalquivir y la torre del Oro, 1898

\section{CONCLUSIONES}

Esta investigación se ha desarrollado en varias líneas: en primer lugar la recuperación y tratamiento documental de las fotografías, incluida la digitalización, con el objeto de su integración en las colecciones del Instituto Valencia de Don Juan; en segundo término se ha realizado el estudio sobre la autora de las imágenes y su aportación a la fotografía española; un tercer aspecto contempla la valoración de los originales en cuanto a fondo y forma; y, por último, se han llevado a cabo las tareas necesarias para que la colección digital generada quede disponible para consulta por la comunidad científica.

Los negativos realizados por Adela Crooke entre los años 1893 y 1902 aportan nuevos datos sobre el papel de la mujer en relación a la fotografía y justifican el interés de los aficionados, reafirmando su actividad práctica (autoría) y documental (coleccionismo).

Se han inventariado y analizado en forma y fondo 276 negativos en vidrio, hasta ahora inéditos, que completan y amplían la excelente colección del Instituto Valencia de Don Juan. Se ha constatado que se corresponden con los positivos del álbum familiar número 12, que se encontraba en gran parte estaba sin identificar y sin referencias cronológicas, por lo que los positivos del álbum han quedado documentados tras esta investigación.

En cuanto a los contenidos, a partir del análisis documental se han establecido nueve temáticas diferentes, destacando por la escasez de originales sobre la materia y por su calidad las fotografías de caza y tauromaquia, la Jura de Alfonso XIII en el Congreso de los Diputados, las vistas de Madrid y Sevilla, y las tomas realizadas en los viajes al extranjero. Dada la cantidad, cualidad y calidad de las imágenes, concluimos que se trata de un fondo de especial interés para la comunidad científica. 


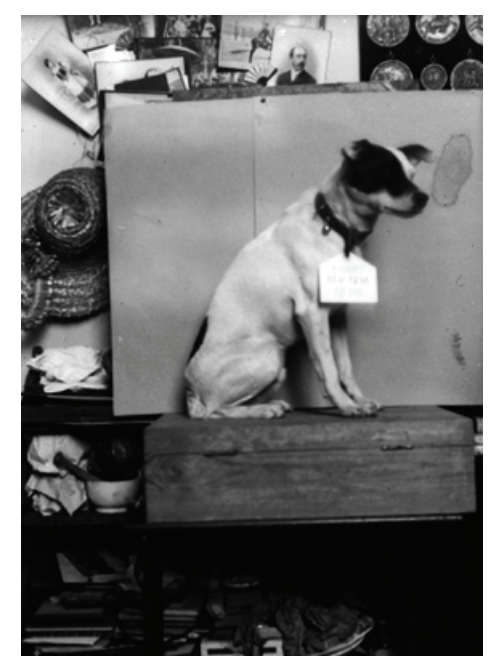

Figura 11. El perro Cherry, 1893

\section{REFERENCIAS BIBLIOGRÁFICAS}

ANDRÉS, G. de. "La fundación del Instituto y museo de Valencia de Don Juan". Ayuntamiento de Madrid. Aula de Cultura. Madrid: Inst. Estudios Madrileños, 1984, pp. 5-32.

BARIANI, Laura. "Manuscritos árabes en el Instituto de Valencia de Don Juan", en Viguera, M. J.; Castillo, C. (edit). Los manuscritos árabes en España y Marruecos, Granada: Junta de Andalucía, 2006, pp. 175-193

BARRIO, J. L. (1998). "Un coleccionista atípico: Don Guillermo Joaquín de Osma", en Goya, 267, 1998, pp. 364-384.

CARABIAS ÁLVARO, Mónica. Lady Clementina Hawarden. Madrid: Orto, 2000.

Delgado, Francisco. "Los aficionados", en Hojas Selectas, abril de 1904. Madrid: Salvat.

Fotografia en las colecciones reales, La. Madrid: Patrimonio Nacional, 1999.

GIL-DÍEZ USANDIZAGA, Ignacio (Editor). Cartes de visite, retratos del siglo XIX en colecciones riojanas. Logroño: Instituto de Estudios Riojanos, 2013.

HERNÁNDEZ BRIZ, Baltasar. "Importancia de la fotografia" en Graphos Ilustrado, enero 1907.

JORDÁN DE URRIÉS, Borja. "Daguerrotipo realizado por Marc Vallete (18441852". Blog de Borja Jordán de Urriés, 2012. Disponible en: http://diarium.usal.es/bjordan. [Consulta: 20 enero 2014]

LÁZARO MARTÍNEZ, Ángeles. Guia-inventario de retratos fotográficos. Madrid: Instituto Valencia de Don Juan, 2003.

LÁZARO MARTíNEZ, Ángeles. Álbum. Colección de fotografia de Marqués de Cerralbo. Madrid: Cerralbo, 2003a 
LÁZARO MARTÍNEZ, Ángeles. Inventario de álbumes fotográficos. Madrid: Instituto Valencia de Don Juan, 2002.

MARTÍN LÓPEZ, Ana María y MUÑOZ GARCÍA, Manuel. Historia de la Real Sociedad Fotográfica. Voluntad de fotógrafos, Segovia: Universidad SEK y RSF, 2004.

MUFFONE, J. La fotografía. Manual para aficionados. Barcelona: Gustavo Gili, 1914.

OCAÑA, J.A. "A propósito de los dibujos inéditos del Instituto Valencia de Don Juan”, en Varia. A.E.A., 294, 2001, pp. 153-163.

OCAÑA, J.A. Los dibujos del Instituto de Valencia de Don Juan de Madrid: Madrid: Instituto Valencia de Don Juan, 1999.

PARTEARROYO LACABA, Cristina. "Crooke y Guzmán, Adelaida", en Diccionario Biográfico Español, XV, 2010, pp. 207. Madrid: Real Academia de la Historia.

PARTEARROYO LACABA, Cristina. "Mecenazgo en Casa-museo de coleccionista. El Instituto de Valencia de Don Juan". Actas de las Jornadas Museos y Mecenazgo, 2007. Madrid: Universidad Rey Juan Carlos, pp.115134.

ROMERO, Alfredo. Fotografia Aragonesa. Ramón y Cajal. Zaragoza: Diputación, 1984.

SÁNCHEZ CANTÓN, F. J. "Retrato de doña Adelaida Crooke y Guzmán de Osma", en Catálogo de las pinturas del Instituto Valencia de Don Juan, 84, 1923. Madrid: IVDJ, pp. 166-167.

SÁNCHEZ VIGIL, Juan Miguel. La fotografia en España. Otra vuelta de tuerca. Gijón: Trea, 2013.

SÁNCHEZ VIGIL, Juan Miguel. Del daguerrotipo a la Instamatic. Gijón: Trea, 2007.

SÁNCHEZ VIGIL, Juan Miguel (Editor). La fotografía en España. De los origenes al siglo XXI. Madrid: Espasa, 2001.

SÁNCHEZ VIGIL, JUAN MIGUEL y OLIVERA ZALDUA, María. La música callada de la fotografía. Miradas de Joaquín Turina. Madrid: Trama Editorial, 2009.

SANTOS QUER, María Ángeles. Guía-inventario de la colección fotográfica del Instituto Valencia de Don Juan. Signaturas: R-12083 y R-12507. Madrid: Biblioteca del Instituto Valencia de Don Juan, 2004, 2009, p. 216 y p. 135

SOUGEZ, MARIE-LOUP. "La mujer en la fotografía española", en La mujer en el arte español. Actas VIII Jornadas de Arte, $26-29$ nov. 1996. Dep. de Historia del Arte Diego Velázquez. Madrid: Centro de Estudios Históricos del CSIC, 1997, pp. 549-558.

VELASCO MAZZONI, K. Fotografia posmortem en el Perú del siglo XIX. Disponible en: http://www.monografias.com/trabajos62 [Consulta: 20 enero 2014]

WARNER MARIEN, Mary. Photography. A cultural history. London: Lawrence King Publishing Ltd, 2002. 


\begin{tabular}{|c|c|c|c|c|}
\hline CóDIGO & TEMA & DESCRIPCIÓN & FECHA & LUGAR \\
\hline $001 \_S \_1 \_1$ & Personajes & Hombre con caballo posando & $\begin{array}{l}1895 / 02 / 0 \\
0\end{array}$ & Madrid \\
\hline $002 \_S \_1 \_2$ & Personajes & Hombre con caballo & \begin{tabular}{|l|}
$1895 / 02 / 0$ \\
0 \\
\end{tabular} & Madrid \\
\hline $003 \_S \_2 \_1$ & Deporte & Partido de Cricket & $\begin{array}{l}1893 / 08 / 0 \\
0\end{array}$ & Eastbourne \\
\hline 004_S_3_1 & Lugares & Puente de Londres & $\begin{array}{l}1893 / 08 / 0 \\
0\end{array}$ & Londres \\
\hline 005_S_4_1 & Lugares & $\begin{array}{l}\text { Puerto de Folkestone con } \\
\text { faro }\end{array}$ & $\begin{array}{l}1893 / 08 / 0 \\
0\end{array}$ & Folkestone \\
\hline 006_S_5_1 & Personajes & $\begin{array}{l}\text { J.J. en bicicleta en calle } \\
\text { Copernic }\end{array}$ & \begin{tabular}{|l|}
$1893 / 10 / 0$ \\
0 \\
\end{tabular} & París \\
\hline 007_S_6_1 & Personajes & $\begin{array}{l}\text { Señora en bicicleta. } \\
\text { Escaparate Terront bicicletas }\end{array}$ & \begin{tabular}{|l|}
$1893 / 10 / 0$ \\
0
\end{tabular} & París \\
\hline $008 \_S \_711$ & Personajes & $\begin{array}{l}\text { J.J. en bicicleta en calle } \\
\text { Copernic }\end{array}$ & \begin{tabular}{|l|}
$1893 / 10 / 0$ \\
0 \\
\end{tabular} & París \\
\hline 009 S 81 & Lugares & Bosque de Bologne & $\begin{array}{l}1893 / 10 / 0 \\
0\end{array}$ & París \\
\hline 010 S 91 & Casa Real & $\begin{array}{l}\text { Calle de Alcalá. Alfonso a } \\
\text { caballo }\end{array}$ & $\begin{array}{l}1893 / 12 / 0 \\
0\end{array}$ & Madrid \\
\hline $011 \_S_{-} 1 \bar{T}_{-}$ & Personajes & Niños en rocas & \begin{tabular}{|l}
$1893 / 08 /$ \\
00
\end{tabular} & Eastbourne \\
\hline $012 \_\mathrm{S} \_11$ & Lugares & Barco velero y muelle & $\begin{array}{l}1893 / 08 / \\
00 \\
\end{array}$ & Eastbourne \\
\hline $013 \_\mathrm{S} \_12$ & Personajes & Playa & $\begin{array}{l}1893 / 08 / \\
00 \\
\end{array}$ & Eastbourne \\
\hline 014_S_13_ & Personajes & Playa. Niñas en bañador & $\begin{array}{l}1893 / 08 / \\
00\end{array}$ & Eastbourne \\
\hline $015 \_S \_14 \_$ & Lugares & $\begin{array}{l}\text { Canal de la Mancha. Vapor. } \\
\text { Tipos }\end{array}$ & $\begin{array}{l}1893 / 08 / \\
00\end{array}$ & Eastbourne \\
\hline $\begin{array}{l}016 \_S \_15 \\
1\end{array}$ & Personajes & Playa. Niñas en primer plano & $\begin{array}{l}1893 / 08 / \\
00\end{array}$ & Eastbourne \\
\hline $\begin{array}{l}017 \_S \_16 \\
1\end{array}$ & Lugares & $\begin{array}{l}\text { Canal de la Mancha. Vapor. } \\
\text { Señora con perro }\end{array}$ & $\begin{array}{l}1893 / 08 / \\
00\end{array}$ & Eastbourne \\
\hline $018 \_S \_17 \_$ & Lugares & Canal de la Mancha. Velero & $\begin{array}{l}1893 / 08 / \\
00 \\
\end{array}$ & Eastbourne \\
\hline $019 \_S_{-} 18 \_$ & Lugares & $\begin{array}{l}\text { Playa. Niños y señora en la } \\
\text { playa }\end{array}$ & $\begin{array}{l}1893 / 08 / \\
00\end{array}$ & Eastbourne \\
\hline 020_S_19_ & Lugares & Barco. Personaje con perro & $\begin{array}{l}1893 / 08 / \\
00\end{array}$ & Eastbourne \\
\hline
\end{tabular}




\begin{tabular}{|c|c|c|c|c|}
\hline 021_S_20_ & Lugares & Embarcadero. Vagón de carga & $\begin{array}{l}1893 / 08 / \\
00\end{array}$ & Boulogne \\
\hline $022 \_\mathrm{S} \_21_{-}$ & Lugares & $\begin{array}{l}\text { Suresnes. Río Sena. } \\
\text { Pescadores }\end{array}$ & $\begin{array}{l}1893 / 10 / \\
00\end{array}$ & París \\
\hline $023 \_S \_22-$ & Lugares & Río Sena. Pescadores & $\begin{array}{l}1893 / 10 / \\
00\end{array}$ & París \\
\hline 024_S_23_ & Lugares & $\begin{array}{l}\text { Calle Almagro. Palacio } \\
\text { Estradas }\end{array}$ & $\begin{array}{l}1893 / 10 / \\
00\end{array}$ & Madrid \\
\hline $025 \_\mathrm{S} \_24$ & Personajes & Dehesa de Mazaranea & $\begin{array}{l}1893 / 11 / \\
00\end{array}$ & Villamiel \\
\hline $026 \_S \_25 \_$ & Lugares & Finca & $\begin{array}{l}1893 / 11 / \\
00\end{array}$ & Villamiel \\
\hline 027_S_26_ & Personajes & Estación. Personajes & $\begin{array}{l}1893 / 11 / \\
00\end{array}$ & Villamiel \\
\hline $028 \_S \_27 \_$ & Lugares & $\begin{array}{l}\text { Vista de la Dehesa de } \\
\text { Mazaranea }\end{array}$ & $\begin{array}{l}1893 / 11 / \\
00\end{array}$ & Villamiel \\
\hline 029_S_28_- & Lugares & $\begin{array}{l}\text { Calle Almagro. Palacio } \\
\text { Estradas }\end{array}$ & $\begin{array}{l}1893 / 11 / \\
00\end{array}$ & Madrid \\
\hline 030_S_29_ & Personajes & $\begin{array}{l}\text { Carrera de San Gerónimo. } \\
\text { Escaparate pastelería }\end{array}$ & $\begin{array}{l}1893 / 12 / \\
00\end{array}$ & Madrid \\
\hline 031_S_30_1 & Lugares & $\begin{array}{l}\text { Plaza de Colón. Tipo en } \\
\text { bicicleta y casas }\end{array}$ & $\begin{array}{l}1893 / 12 / 0 \\
0\end{array}$ & Madrid \\
\hline 032_S_31_1 & Personajes & $\begin{array}{l}\text { Paseo de la Castellana. } \\
\text { Alfonso montando }\end{array}$ & $\begin{array}{l}1893 / 11 / 0 \\
0\end{array}$ & Madrid \\
\hline 033_S_32_1 & Deporte & Partido de Cricket & $\begin{array}{l}1893 / 08 / 0 \\
0\end{array}$ & $\begin{array}{l}\text { Eastbourn } \\
\mathrm{e}\end{array}$ \\
\hline 034_S_33_1 & Lugares & $\begin{array}{l}\text { Plaza de Cibeles. Palacio de } \\
\text { Linares }\end{array}$ & \begin{tabular}{|l|l}
$1893 / 12 / 0$ \\
0
\end{tabular} & Madrid \\
\hline 035_S_34_1 & Personajes & $\begin{array}{l}\text { Plaza de Cibeles. Torre-Arias } \\
\text { y señora }\end{array}$ & $\begin{array}{l}1893 / 12 / 0 \\
0\end{array}$ & Madrid \\
\hline 036_S_35_1 & Lugares & Vapor & $\begin{array}{l}1893 / 08 / 0 \\
0\end{array}$ & \begin{tabular}{|l} 
Eastbourn \\
$\mathrm{e}$
\end{tabular} \\
\hline 037_S_36_1 & Personajes & $\begin{array}{l}\text { Paseo del Prado. Padre, } \\
\text { María y Cherry }\end{array}$ & $\begin{array}{l}1893 / 12 / 0 \\
0 \\
\end{array}$ & Madrid \\
\hline 038 S $37 \quad 1$ & Personajes & $\begin{array}{l}\text { Paseo de la Castellana. } \\
\text { "Mamá y Matilde" }\end{array}$ & \begin{tabular}{|l|l|}
$1893 / 12 / 0$ \\
0 \\
\end{tabular} & Madrid \\
\hline $039 \_\mathrm{S} \_38 \_1$ & Personajes & $\begin{array}{l}\text { Carrera San Jerónimo. } \\
\text { Linares Rivas y Enrique }\end{array}$ & $\begin{array}{l}1893 / 12 / 0 \\
0 \\
\end{array}$ & Madrid \\
\hline 040_S_39_1 & Personajes & $\begin{array}{l}\text { Plaza de Colón. Tipo a } \\
\text { caballo }\end{array}$ & $\begin{array}{l}1893 / 12 / 0 \\
0\end{array}$ & Madrid \\
\hline 041_S_40_1 & Personajes & $\begin{array}{l}\text { Paseo de la Castellana. El } \\
\text { matrimonio Soriano }\end{array}$ & $\begin{array}{l}1893 / 12 / 0 \\
0\end{array}$ & Madrid \\
\hline
\end{tabular}




\begin{tabular}{|c|c|c|c|c|}
\hline 042_S_41_1 & Animales & Perro (Cherry) & $\begin{array}{l}1893 / 12 / 0 \\
0\end{array}$ & Madrid \\
\hline 043 S 421 & Lugares & $\begin{array}{l}\text { Palacio de los Valencia de } \\
\text { Don Juan }\end{array}$ & $\begin{array}{l}1893 / 12 / 0 \\
0\end{array}$ & Madrid \\
\hline $044 \_$S $43 \_1$ & Animales & Perro (Cherry) calendario & $\begin{array}{l}1893 / 12 / 0 \\
0\end{array}$ & Madrid \\
\hline 045_S_44_1 & Animales & $\begin{array}{l}\text { Paseo de la Castellana. } \\
\text { Cherry jugando }\end{array}$ & $\begin{array}{l}1893 / 12 / 0 \\
0\end{array}$ & Madrid \\
\hline $046 \_$S $45 \_1$ & Animales & $\begin{array}{l}\text { Paseo de la Castellana. } \\
\text { Cherry jugando }\end{array}$ & $\begin{array}{l}1893 / 12 / 0 \\
0\end{array}$ & Madrid \\
\hline 047 S 461 & Animales & $\begin{array}{l}\text { Paseo de la Castellana. } \\
\text { Cherry jugando }\end{array}$ & $\begin{array}{l}1893 / 12 / 0 \\
0\end{array}$ & Madrid \\
\hline 048_S_47_1 & Lugares & $\begin{array}{l}\text { Paisaje entre Madrid y } \\
\text { Toledo desde el tren }\end{array}$ & $\begin{array}{l}1893 / 12 / 0 \\
0\end{array}$ & Toledo \\
\hline $049 \_S \_48 \_1$ & Personajes & $\begin{array}{l}\text { Paseo de la Castellana. } \\
\text { Señor, señora y niña }\end{array}$ & $\begin{array}{l}1893 / 12 / 0 \\
0\end{array}$ & Madrid \\
\hline 050_S_49_1 & Caza & $\begin{array}{l}\text { Grupo de cazadores en } \\
\text { campo abierto }\end{array}$ & $\begin{array}{l}1894 / 02 / 0 \\
0\end{array}$ & Aranjuez \\
\hline 051_S_50_1 & Caza & $\begin{array}{l}\text { Finca Flamenca. Grupo de } \\
\text { cazadores }\end{array}$ & $\begin{array}{l}1894 / 02 / 0 \\
0\end{array}$ & Aranjuez \\
\hline 052_S_50_2 & Caza & $\begin{array}{l}\text { Finca Flamenca. Grupo de } \\
\text { cazadores }\end{array}$ & $\begin{array}{l}1894 / 02 / 0 \\
0\end{array}$ & Aranjuez \\
\hline 053 S 511 & Personajes & $\begin{array}{l}\text { Finca Flamenca. Duquesa de } \\
\text { Alba e hijos }\end{array}$ & $\begin{array}{l}1894 / 02 / 0 \\
0\end{array}$ & Aranjuez \\
\hline 054 S 512 & Personajes & $\begin{array}{l}\text { Finca Flamenca. Duquesa de } \\
\text { Alba e hijos }\end{array}$ & $\begin{array}{l}1894 / 02 / 0 \\
0\end{array}$ & Aranjuez \\
\hline 055_S_52_1 & Personajes & $\begin{array}{l}\text { Finca Flamenca. Paseando } \\
\text { con niños y Cherry }\end{array}$ & $\begin{array}{l}1894 / 02 / 0 \\
0\end{array}$ & Aranjuez \\
\hline 056_S_53_1 & Caza & $\begin{array}{l}\text { Cacería de liebres. Cazadores } \\
\text { a caballo }\end{array}$ & $\begin{array}{l}1894 / 02 / 0 \\
0\end{array}$ & Aranjuez \\
\hline 057_S_53_2 & Caza & $\begin{array}{l}\text { Cacería de liebres. Cazadores } \\
\text { a caballo }\end{array}$ & $\begin{array}{l}1894 / 02 / 0 \\
0\end{array}$ & Aranjuez \\
\hline $058 \_\mathrm{S} \_54 \_1$ & Caza & $\begin{array}{l}\text { Finca Flamenca. Grupo de } \\
\text { cazadores }\end{array}$ & $\begin{array}{l}1894 / 02 / 0 \\
0\end{array}$ & Aranjuez \\
\hline $059 \_S \_54 \_2$ & Caza & $\begin{array}{l}\text { Finca Flamenca. Grupo de } \\
\text { cazadores }\end{array}$ & $\begin{array}{l}1894 / 02 / 0 \\
0\end{array}$ & Aranjuez \\
\hline 060_S_55_1 & Caza & $\begin{array}{l}\text { Finca Flamenca. Grupo de } \\
\text { cazadores }\end{array}$ & $\begin{array}{l}1894 / 02 / 0 \\
0\end{array}$ & Aranjuez \\
\hline $061 \_S \_55 \_2$ & Caza & $\begin{array}{l}\text { Finca Flamenca. Grupo de } \\
\text { cazadores }\end{array}$ & $\begin{array}{l}1894 / 02 / 0 \\
0\end{array}$ & Aranjuez \\
\hline $062 \_S \_56 \_1$ & Caza & $\begin{array}{l}\text { Finca Flamenca. "Pocholo y } \\
\text { Gomar" }\end{array}$ & $\begin{array}{l}1894 / 02 / 0 \\
0\end{array}$ & Aranjuez \\
\hline
\end{tabular}




\begin{tabular}{|c|c|c|c|c|}
\hline 063_S_57_1 & Caza & Finca Flamenca. "Pocholo" & \begin{tabular}{|l|}
$1894 / 02 / 0$ \\
0 \\
\end{tabular} & Aranjuez \\
\hline $064 \_S \_58 \_1$ & Personajes & Tipos a caballo & \begin{tabular}{|l|l|}
$1894 / 01 / 0$ \\
0
\end{tabular} & Alcorcón \\
\hline 065 S_58_2 & Personajes & Tipos a caballo & \begin{tabular}{|l}
$1894 / 01 / 0$ \\
0
\end{tabular} & Alcorcón \\
\hline 066_S_59_1 & Personajes & Andrés montando a caballo & $\begin{array}{l}1894 / 01 / 0 \\
0\end{array}$ & Alcorcón \\
\hline 067_S_60_1 & Personajes & Santoña montando a caballo & $\begin{array}{l}1894 / 02 / 0 \\
0\end{array}$ & Alcorcón \\
\hline 068_S_61_1 & Lugares & $\begin{array}{l}\text { Palacio de Valencia de Don } \\
\text { Juan con nieve }\end{array}$ & $\begin{array}{l}1894 / 01 / 0 \\
0\end{array}$ & Madrid \\
\hline 069_S_62_1 & Lugares & $\begin{array}{l}\text { Palacio Valencia de Don } \\
\text { Juan con nieve }\end{array}$ & $\begin{array}{l}1894 / 01 / 0 \\
0\end{array}$ & Madrid \\
\hline 070_S_63_1 & Personajes & $\begin{array}{l}\text { Paseo de la Castellana. } \\
\text { "Alfonso Maceda y Billy" }\end{array}$ & $\begin{array}{l}1893 / 12 / 0 \\
0\end{array}$ & Madrid \\
\hline 071_S_64_1 & Personajes & $\begin{array}{l}\text { Alfonso montando al caballo } \\
\text { Buen Chico }\end{array}$ & $\begin{array}{l}1894 / 01 / 0 \\
0\end{array}$ & Madrid \\
\hline 072_S_64_2 & Personajes & $\begin{array}{l}\text { Alfonso montando al caballo } \\
\text { Buen Chico }\end{array}$ & $\begin{array}{l}1894 / 01 / 0 \\
0\end{array}$ & Madrid \\
\hline 073_S_65_1 & Militares & $\begin{array}{l}\text { Calle Alcalá. Grupo de } \\
\text { artilleros }\end{array}$ & $\begin{array}{l}1893 / 12 / 0 \\
0\end{array}$ & Madrid \\
\hline 074_S_66_1 & Personajes & $\begin{array}{l}\text { Paseo de la Castellana. } \\
\text { Desfile de artillero }\end{array}$ & \begin{tabular}{|l|l|}
$1893 / 12 / 0$ \\
0 \\
\end{tabular} & Madrid \\
\hline 075_S_67_1 & Transporte & $\begin{array}{l}\text { Coche de caballos "Mylord } \\
\text { de María" }\end{array}$ & \begin{tabular}{|l}
$1894 / 02 / 0$ \\
0
\end{tabular} & Madrid \\
\hline 076_S_67_2 & Transporte & $\begin{array}{l}\text { Coche de caballos "Mylord } \\
\text { de María" }\end{array}$ & \begin{tabular}{|l|l|}
$1894 / 02 / 0$ \\
0 \\
\end{tabular} & Madrid \\
\hline 077_S_68_1 & Militares & Calle Alcalá 23. Artillero & $\begin{array}{l}1893 / 12 / 0 \\
0\end{array}$ & Madrid \\
\hline 078_S_69_1 & Animales & Perro en el campo (Cherry) & $\begin{array}{l}1894 / 02 / 0 \\
0 \\
\end{array}$ & Madrid \\
\hline 079 S_69_2 & Animales & Perro en el campo (Cherry) & $\begin{array}{l}1894 / 02 / 0 \\
0\end{array}$ & Madrid \\
\hline 080_S $70 \_1$ & Animales & Perro en el campo (Cherry) & \begin{tabular}{|l|l|}
$1894 / 02 / 0$ \\
0 \\
\end{tabular} & Madrid \\
\hline 081_S $70 \_2$ & Animales & Perro en el campo (Cherry) & \begin{tabular}{|l}
$1894 / 02 / 0$ \\
0 \\
\end{tabular} & Madrid \\
\hline 082_S_71_1 & Transporte & $\begin{array}{l}\text { Break de Alfonso. Coche de } \\
\text { caballo }\end{array}$ & $\begin{array}{l}1894 / 02 / 0 \\
0\end{array}$ & Madrid \\
\hline 083_S_72_1 & Transporte & $\begin{array}{l}\text { Finca Flamenca. Coches de } \\
\text { caza }\end{array}$ & $\begin{array}{l}1894 / 02 / 0 \\
0\end{array}$ & Aranjuez \\
\hline
\end{tabular}




\begin{tabular}{|c|c|c|c|c|}
\hline 084_S_73_1 & Personajes & $\begin{array}{l}\text { Venta de Alcorcón. Alfonso } \\
\text { preparando su coche }\end{array}$ & $\begin{array}{l}1894 / 01 / 0 \\
0\end{array}$ & Alcorcón \\
\hline 085 S 741 & Personajes & Marianito y Andrés a caballo & $\begin{array}{l}1894 / 01 / 0 \\
0\end{array}$ & Alcorcón \\
\hline 086_S_74_2 & Personajes & Marianito y Andrés a caballo & \begin{tabular}{|l|}
$1894 / 01 / 0$ \\
0 \\
\end{tabular} & Alcorcón \\
\hline 087_S_75_1 & Militares & Calle Alcalá 25. Artillero & $\begin{array}{l}1893 / 12 / 0 \\
0 \\
\end{array}$ & Madrid \\
\hline $088 \_$S_76_1 & Personajes & Calle Alcalá. Chaparro? & $\begin{array}{l}1893 / 12 / 0 \\
0 \\
\end{array}$ & Madrid \\
\hline 089 S $77 \quad 1$ & Personajes & Alfonso montando & $\begin{array}{l}1893 / 12 / 0 \\
0\end{array}$ & Madrid \\
\hline 090_S_78_1 & Personajes & $\begin{array}{l}\text { Paseo de la Castellan. } \\
\text { Joaquina, Mariano y Billy }\end{array}$ & $\begin{array}{l}1893 / 12 / 0 \\
0\end{array}$ & Madrid \\
\hline 091_S_79_1 & Transporte & $\begin{array}{l}\text { Paseo de la Castellana. } \\
\text { Tranvía tirado de mulas }\end{array}$ & $\begin{array}{l}1893 / 12 / 0 \\
0\end{array}$ & Madrid \\
\hline 092_S_80_1 & Personajes & $\begin{array}{l}\mathrm{P}^{\circ} \text { Castellana. Alfonso } \\
\text { montando la jaca Laura }\end{array}$ & $\begin{array}{l}1893 / 12 / 0 \\
0 \\
\end{array}$ & Madrid \\
\hline 093_S_81_1 & Personajes & $\begin{array}{l}\mathrm{P}^{\circ} \text { de la Castellana. Alfonso } \\
\text { y Manolo Martorell }\end{array}$ & \begin{tabular}{|l|}
$1893 / 12 / 0$ \\
0 \\
\end{tabular} & Madrid \\
\hline 094_S_82_1 & Personajes & $\begin{array}{l}\text { Paseo de la Castellana. } \\
\text { Mariano en su charriette }\end{array}$ & $\begin{array}{l}1893 / 12 / 0 \\
0\end{array}$ & Madrid \\
\hline 095 S $83 \_1$ & Personajes & $\begin{array}{l}\text { Carrera de San Jerónimo } 33 . \\
\text { Personajes }\end{array}$ & $\begin{array}{l}1893 / 12 / 0 \\
0\end{array}$ & Madrid \\
\hline 096 S 841 & Personajes & $\begin{array}{l}\text { Carrera de San Jerónimo } 33 . \\
\text { Dos señoras }\end{array}$ & $\begin{array}{l}1893 / 12 / 0 \\
0\end{array}$ & Madrid \\
\hline 097 S 851 & Personajes & $\begin{array}{l}\text { Carrera de San Jerónimo } 33 . \\
\text { Enrique Diselier }\end{array}$ & $\begin{array}{l}1893 / 12 / 0 \\
0\end{array}$ & Madrid \\
\hline 098_S_86_1 & Personajes & $\begin{array}{l}\mathrm{P}^{\circ} \text { Castellana. Alfonso } \\
\text { montando a Buen Chico }\end{array}$ & $\begin{array}{l}1893 / 12 / 0 \\
0\end{array}$ & Madrid \\
\hline 099_S_87_1 & Personajes & $\begin{array}{l}\text { Carrera de San Jerónimo, } 33 . \\
\text { Enrique Dielier }\end{array}$ & $\begin{array}{l}1893 / 12 / 0 \\
0\end{array}$ & Madrid \\
\hline $100 \_\mathrm{S} 88 \_1$ & Personajes & $\begin{array}{l}\text { Calle Fortuna. Alfonso } \\
\text { montando a Buen Chico }\end{array}$ & $\begin{array}{l}1893 / 12 / 0 \\
0\end{array}$ & Madrid \\
\hline 101_S_89_1 & Animales & $\begin{array}{l}\text { Finca Flamenca. Galgos de } \\
\text { Carlos Alba }\end{array}$ & \begin{tabular}{|l|l|}
$1894 / 02 / 0$ \\
0 \\
\end{tabular} & Aranjuez \\
\hline 102 S_89_2 & Animales & $\begin{array}{l}\text { Finca Flamenca. Galgos de } \\
\text { Carlos Alba }\end{array}$ & $\begin{array}{l}1894 / 02 / 0 \\
0\end{array}$ & Aranjuez \\
\hline 103_S_90 & Animales & Finca Flamenca. Galgos & $\begin{array}{l}1894 / 02 / 0 \\
0\end{array}$ & Aranjuez \\
\hline $\begin{array}{l}104 \_S \_90 \\
2\end{array}$ & Caza & Finca Flamenca. Don Dimas & $1894 / 02 / 00$ & Aranjuez \\
\hline
\end{tabular}




\begin{tabular}{|c|c|c|c|c|}
\hline 105_S_91_ & Personajes & $\begin{array}{l}\text { Finca Flamenca. Manolete } \\
\text { montando a Donald }\end{array}$ & $1894 / 02 / 00$ & Aranjuez \\
\hline 106_S_92_ & Transporte & $\begin{array}{l}\text { Coche de caballos. Break de } \\
\text { Mariano }\end{array}$ & $1894 / 01 / 00$ & Alcorcón \\
\hline 107_S_92_ & Transporte & $\begin{array}{l}\text { Coche de caballos. Break de } \\
\text { Mariano }\end{array}$ & $1894 / 01 / 00$ & Alcorcón \\
\hline 108_S_93_ & Personajes & Andrés a caballo & $1894 / 01 / 00$ & Alcorcón \\
\hline 109_S_94_ & Lugares & Calle de Fortuny nevada & $1894 / 01 / 00$ & Madrid \\
\hline 110_S_95_ & $\begin{array}{l}\text { Tauromaqui } \\
\text { a }\end{array}$ & $\begin{array}{l}\text { Corrida de toros. Suerte de } \\
\text { varas }\end{array}$ & $1894 / 05 / 30$ & Aranjuez \\
\hline 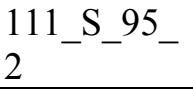 & $\begin{array}{l}\text { Tauromaqui } \\
\text { a }\end{array}$ & $\begin{array}{l}\text { Corrida de toros. Suerte de } \\
\text { varas }\end{array}$ & $1894 / 05 / 30$ & Aranjuez \\
\hline 112_S_96_ & Transporte & $\begin{array}{l}\text { Coche de vapor y coche de } \\
\text { caballos }\end{array}$ & $1894 / 05 / 30$ & Aranjuez \\
\hline 113_S_97_- & Animales & $\begin{array}{l}\text { Carreras de caballos. Caballo } \\
\text { Arfe }\end{array}$ & $1894 / 05 / 31$ & Aranjuez \\
\hline $114 \_S \_98 \_$ & Transporte & $\begin{array}{l}\text { Carreras de caballos. Coches } \\
\text { reales }\end{array}$ & $1894 / 04 / 00$ & Madrid \\
\hline 115_S_98_ & Transporte & $\begin{array}{l}\text { Carreras de caballos. Coches } \\
\text { reales }\end{array}$ & $1894 / 04 / 00$ & Madrid \\
\hline 116_S_99_ & Personajes & $\begin{array}{l}\text { Soto de la Ciudad. Retrato de } \\
\text { grupo }\end{array}$ & $1894 / 05 / 00$ & Alcalá \\
\hline 117_S_99_ & Personajes & $\begin{array}{l}\text { Soto de la Ciudad. Retrato de } \\
\text { grupo }\end{array}$ & $1894 / 05 / 00$ & Alcalá \\
\hline 118_S_100 & Animales & Caballo Sarah de Torre-Arías & $1895 / 02 / 00$ & Madrid \\
\hline 119_S_100 & Animales & Caballo Sarah de Torre-Arías & $1895 / 02 / 00$ & Madrid \\
\hline $120 \_\mathrm{S} \_101$ & Animales & Caballo Sarah de Torre-Arías & $1895 / 02 / 00$ & Madrid \\
\hline 121_S_101 & Animales & Caballo Sarah de Torre-Arías & $1895 / 02 / 00$ & Madrid \\
\hline 122_S_102 & $\begin{array}{l}\text { Tauromaqui } \\
\text { a }\end{array}$ & Soto. Rosario fotografiando & $1894 / 05 / 00$ & Alcalá \\
\hline 123_S_103 & Casa Real & $\begin{array}{l}\text { Soto. Isabel de Borbón y } \\
\text { yeguas de Uraeta }\end{array}$ & $1894 / 05 / 00$ & Alcalá \\
\hline 124_S_104 & $\begin{array}{l}\text { Tauromaqui } \\
\text { a }\end{array}$ & $\begin{array}{l}\text { Soto de la Ciudad. Toros en } \\
\text { el campo }\end{array}$ & $1894 / 05 / 00$ & Alcalá \\
\hline $\begin{array}{l}125 \_S \_104 \\
2\end{array}$ & $\begin{array}{l}\text { Tauromaqui } \\
\text { a }\end{array}$ & $\begin{array}{l}\text { Soto de la Ciudad. Toros en } \\
\text { el campo }\end{array}$ & $1894 / 05 / 00$ & Alcalá \\
\hline
\end{tabular}




\begin{tabular}{|c|c|c|c|c|}
\hline 126_S_105 & Deporte & $\begin{array}{l}\text { Grupo de hombres y mujeres } \\
\text { en las carreras }\end{array}$ & $1894 / 04 / 00$ & Madrid \\
\hline $\begin{array}{l}127 \_S \_105 \\
2\end{array}$ & Deporte & $\begin{array}{l}\text { Grupo de hombres y mujeres } \\
\text { ne las carreras }\end{array}$ & $1894 / 04 / 00$ & Madrid \\
\hline 128_S_106 & Personajes & $\begin{array}{l}\text { Carreras de caballos. Dos } \\
\text { hombres y una mujer }\end{array}$ & $1894 / 04 / 00$ & Madrid \\
\hline $\begin{array}{l}129 \_S \_106 \\
2\end{array}$ & Deporte & $\begin{array}{l}\text { Carreras de caballos. Museo } \\
\text { de Ciencias Naturales }\end{array}$ & $1894 / 04 / 00$ & Madrid \\
\hline 130_S_107 & Transporte & $\begin{array}{l}\text { Carreras de caballos. Coches } \\
\text { reales }\end{array}$ & $1894 / 04 / 00$ & Madrid \\
\hline 131_S_107 & Deporte & $\begin{array}{l}\text { Carreras de caballos. Coches } \\
\text { reales }\end{array}$ & $1894 / 04 / 00$ & Madrid \\
\hline 132_S_108 & Deporte & Carreras de caballos & $1894 / 04 / 00$ & Madrid \\
\hline 133_S_108 & Deporte & Carreras de caballos & $1894 / 04 / 00$ & Madrid \\
\hline $\begin{array}{l}134 \_S \_109 \\
1\end{array}$ & Personajes & Carreras de caballos & $1894 / 04 / 00$ & Madrid \\
\hline 135_S_109 & Deporte & $\begin{array}{l}\text { Carreras de caballos. Tribuna } \\
\text { Real }\end{array}$ & $1894 / 04 / 00$ & Madrid \\
\hline $\begin{array}{l}136 \_S \_110 \\
1\end{array}$ & Personajes & Cuatro hombres de perfil & $1894 / 04 / 00$ & Madrid \\
\hline 137_S_111 & Lugares & Campo del Moro & $1894 / 03 / 00$ & Madrid \\
\hline 138_S_112 & Lugares & Vista de El Pardo & $1894 / 03 / 00$ & Madrid \\
\hline 139_S_113 & Lugares & Palacio Real. Entrada & $1894 / 03 / 00$ & Madrid \\
\hline $\begin{array}{l}140 \_S \_114 \\
1\end{array}$ & Casa Real & $\begin{array}{l}\text { Alfonso XIII en coche de } \\
\text { caballos }\end{array}$ & $1894 / 03 / 00$ & Madrid \\
\hline 141_S_115 & Casa Real & $\begin{array}{l}\text { Alfonso XIII en coche de } \\
\text { caballos }\end{array}$ & $1894 / 03 / 00$ & Madrid \\
\hline 142_S_116 & Casa Real & $\begin{array}{l}\text { La Reina y Rosario junto a } \\
\text { una casa }\end{array}$ & $1894 / 03 / 00$ & Madrid \\
\hline $\begin{array}{c}143 \_S \_116 \\
2\end{array}$ & Casa Real & $\begin{array}{l}\text { La Reina y Rosario. En el } \\
\text { fondo arboleda }\end{array}$ & $1894 / 03 / 00$ & Madrid \\
\hline 144_S_117 & Lugares & $\begin{array}{l}\text { Palacio Real. Lateral con } \\
\text { calle peatonal }\end{array}$ & $1894 / 03 / 00$ & Madrid \\
\hline 145_S_117 & Lugares & Palacio Real. Plaza & $1894 / 03 / 00$ & Madrid \\
\hline $\begin{array}{l}146 \_S \_118 \\
1\end{array}$ & Lugares & $\begin{array}{l}\text { Campo del Moro. Caseta en } \\
\text { el medio }\end{array}$ & $1894 / 03 / 00$ & Madrid \\
\hline
\end{tabular}




\begin{tabular}{|c|c|c|c|c|}
\hline 147_S_119 & Casa Real & Infantas en coche de caballos & $1894 / 03 / 00$ & Aranjuez \\
\hline $\begin{array}{c}\overline{1} \\
2\end{array}$ & Casa Real & Infantas en coche de caballos & $1894 / 03 / 00$ & Madrid \\
\hline 149_S_120 & Personajes & $\begin{array}{l}\text { Finca Flamenca. Dos } \\
\text { hombres a caballo }\end{array}$ & $1894 / 03 / 00$ & Aranjuez \\
\hline 150_S_121 & Caza & Grupo de hombres de caza & $1894 / 02 / 00$ & Aranjuez \\
\hline 151_S_121 & Caza & Grupo de hombres de caza & $1894 / 02 / 00$ & Aranjuez \\
\hline $152 \_S \_122$ & Caza & Grupo de hombres de caza & $1894 / 02 / 00$ & Aranjuez \\
\hline $\begin{array}{l}153 \_S \_122 \\
2\end{array}$ & Caza & Grupo de hombres de caza & $1894 / 02 / 00$ & Aranjuez \\
\hline 154_S_123 & Animales & $\begin{array}{l}\text { Finca Flamenca. Perro de la } \\
\text { familia }\end{array}$ & $1894 / 02 / 00$ & Aranjuez \\
\hline 155_S_123 & Animales & $\begin{array}{l}\text { Finca Flamenca. Perro de la } \\
\text { familia }\end{array}$ & $1894 / 02 / 00$ & Aranjuez \\
\hline 156_S_124 & Animales & $\begin{array}{l}\text { Finca Flamenca. Perro de la } \\
\text { familia }\end{array}$ & $1894 / 02 / 00$ & Aranjuez \\
\hline $\begin{array}{l}156 \_S \_124 \\
2\end{array}$ & Animales & $\begin{array}{l}\text { Finca Flamenca. Perro de la } \\
\text { familia }\end{array}$ & $1894 / 02 / 00$ & Aranjuez \\
\hline $\begin{array}{l}158 \_S \_125 \\
1\end{array}$ & Animales & $\begin{array}{l}\text { Finca Flamenca. Perro con } \\
\text { una liebre }\end{array}$ & $1894 / 02 / 00$ & Aranjuez \\
\hline $\begin{array}{l}159 \_S \_125 \\
2\end{array}$ & Animales & $\begin{array}{l}\text { Finca Flamenca. Perro con } \\
\text { una liebre }\end{array}$ & $1894 / 02 / 00$ & Aranjuez \\
\hline 160_S_126 & Personajes & Finca Romanillos. Retrato & $1894 / 03 / 00$ & Boadilla \\
\hline 161_S_127 & Personajes & $\begin{array}{l}\text { Madame Soriano de negro en } \\
\text { el tiro de pichón }\end{array}$ & $1894 / 03 / 00$ & Madrid \\
\hline 162_S_128 & Personajes & $\begin{array}{l}\text { Romanillos. Retrato en la } \\
\text { finca }\end{array}$ & $1894 / 03 / 00$ & Boadilla \\
\hline $\begin{array}{c}163 \_S \_128 \\
2\end{array}$ & Personajes & $\begin{array}{l}\text { Romanillos. Retrato en la } \\
\text { finca }\end{array}$ & $1894 / 03 / 00$ & Boadilla \\
\hline $\begin{array}{c}164 \_S \_129 \\
1\end{array}$ & Transporte & $\begin{array}{l}\text { Coche de caballos. Dos } \\
\text { hombres y una mujer }\end{array}$ & $1894 / 04 / 00$ & Madrid \\
\hline 165_S_129 & Transporte & $\begin{array}{l}\text { Coche de caballos. Cuatro } \\
\text { hombres y una mujer. }\end{array}$ & $1894 / 04 / 00$ & Madrid \\
\hline 166_S_130 & Transporte & $\begin{array}{l}\text { Coche de caballos con dos } \\
\text { hombres y una mujer }\end{array}$ & $1894 / 03 / 00$ & Madrid \\
\hline $\begin{array}{l}167 \_S \_131 \\
1\end{array}$ & Personajes & $\begin{array}{l}\text { Paseo de la Castellana. Los } \\
\text { hijos de Torre Arias }\end{array}$ & $1894 / 03 / 00$ & Madrid \\
\hline
\end{tabular}




\begin{tabular}{|c|c|c|c|c|}
\hline $168 \_S \_132$ & Casa Real & $\begin{array}{l}\text { Isabel de Borbón y señora en } \\
\text { tiro de pichón }\end{array}$ & $1894 / 03 / 00$ & Madrid \\
\hline $\begin{array}{c}169 \_S \_133 \\
1\end{array}$ & Personajes & $\begin{array}{l}\text { El Duque de Alba en el tiro } \\
\text { de pichón }\end{array}$ & $1894 / 03 / 00$ & Madrid \\
\hline 170_S_133 & Personajes & $\begin{array}{l}\text { El Duque de Alba en el tiro } \\
\text { de pichón }\end{array}$ & $1894 / 03 / 00$ & Madrid \\
\hline $\begin{array}{l}171 \_S \_134 \\
1\end{array}$ & Tauromaquia & $\begin{array}{l}\text { Plaza de toros de Aranjuez. } \\
\text { Suerte de varas }\end{array}$ & $1894 / 05 / 30$ & Aranjuez \\
\hline 172_S_134 & Tauromaquia & $\begin{array}{l}\text { Plaza de toros de Aranjuez. } \\
\text { Suerte de varas }\end{array}$ & $1894 / 05 / 30$ & Aranjuez \\
\hline 173_S_135 & Personajes & $\begin{array}{l}\text { Calle Fortuna. Alfonso } \\
\text { montando a Buen Chico }\end{array}$ & $1894 / 01 / 00$ & Madrid \\
\hline $\begin{array}{l}174 \_S \_136 \\
1\end{array}$ & Tauromaquia & $\begin{array}{l}\text { Plaza de toros de Aranjuez. } \\
\text { Paseíllo }\end{array}$ & $1894 / 05 / 30$ & Aranjuez \\
\hline 175_S_137 & Militares & $\begin{array}{l}\text { Grupo de oficiales y paisanos } \\
\text { a pie }\end{array}$ & $1894 / 05 / 31$ & Aranjuez \\
\hline 176_S_138 & Militares & Grupo de oficiales a caballo & $1894 / 05 / 31$ & Aranjuez \\
\hline $\begin{array}{l}177 \_S \_139 \\
1\end{array}$ & Personajes & $\begin{array}{l}\text { Tres mujeres y cinco } \\
\text { hombres posando }\end{array}$ & $1894 / 05 / 31$ & Aranjuez \\
\hline 178_S_140 & Militares & $\begin{array}{l}\text { Cuatro oficiales y uno a } \\
\text { caballo }\end{array}$ & $1894 / 05 / 31$ & Aranjuez \\
\hline $\begin{array}{l}179 \_S \_141 \\
1\end{array}$ & Animales & $\begin{array}{l}\text { Caballo "La Paladilla" } \\
\text { cortado }\end{array}$ & $1894 / 05 / 31$ & Aranjuez \\
\hline 180_S_141 & Deporte & Grupo de hombres y caballos & $1894 / 05 / 31$ & Aranjuez \\
\hline 181_S_142 & Personajes & $\begin{array}{l}\text { La Flamenca. Grupo en el } \\
\text { apeadero }\end{array}$ & $1894 / 05 / 31$ & Aranjuez \\
\hline $\begin{array}{l}182 \_S \_142 \\
2\end{array}$ & Personajes & $\begin{array}{l}\text { Hombre y mujer. Al fondo } \\
\text { coche de caballos }\end{array}$ & $1894 / 05 / 31$ & Aranjuez \\
\hline 183_S_143 & Animales & Caballo "Sarah" y cuidador & $1895 / 02 / 00$ & Madrid \\
\hline 184_S_143 & Animales & Caballo "Sarah" & $1895 / 02 / 00$ & Madrid \\
\hline $\begin{array}{l}185 \_S \_144 \\
1\end{array}$ & Personajes & Enganche de caballos & $1895 / 01 / 00$ & Madrid \\
\hline $\begin{array}{c}186 \_S \_145 \\
1\end{array}$ & Lugares & Estanque con cisne & $1894 / 09 / 00$ & Oxford \\
\hline $\begin{array}{l}187 \_S \_146 \\
1\end{array}$ & Lugares & Casa de campo de ladrillo & $1894 / 09 / 00$ & Oxford \\
\hline $\begin{array}{l}188 \_S \_147 \\
1\end{array}$ & Lugares & Pembroke Collage & $1894 / 09 / 00$ & Oxford \\
\hline
\end{tabular}




\begin{tabular}{|c|c|c|c|c|}
\hline $\begin{array}{l}189 \_S \_148 \\
1\end{array}$ & Personajes & Pembroke Collage & $1894 / 09 / 00$ & Oxford \\
\hline 190_S_149 & Personajes & Pembroke Collage & $1894 / 09 / 00$ & Oxford \\
\hline 191_S_150 & Personajes & Playa & $1894 / 10 / 00$ & Biarritz \\
\hline 192_S_150 & Personajes & Playa & $1894 / 10 / 00$ & Biarritz \\
\hline 193_S_151 & Personajes & Playa & $1894 / 10 / 00$ & Biarritz \\
\hline $\begin{array}{l}194 \_S \_152 \\
1\end{array}$ & Personajes & Estación & $1894 / 10 / 00$ & Biarritz \\
\hline 195_S_153 & Personajes & $\begin{array}{l}\text { Niño con perro sentado en } \\
\text { las escaleras }\end{array}$ & $1894 / 10 / 00$ & Dave \\
\hline 196_S_154 & Personajes & $\begin{array}{l}\text { Dos niños con perro sentados } \\
\text { en escalera }\end{array}$ & $1894 / 10 / 00$ & Dave \\
\hline $\begin{array}{l}197 \_S \_154 \\
2\end{array}$ & Personajes & $\begin{array}{l}\text { Grupo de hombres y mujeres } \\
\text { en escaleras }\end{array}$ & $1894 / 10 / 00$ & Dave \\
\hline $\begin{array}{l}198 \_S \_155 \\
1\end{array}$ & Personajes & Dos hombres y una mujer & $1894 / 10 / 00$ & Dave \\
\hline 199_S_155 & Caza & $\begin{array}{l}\text { Grupo de hombres y mujeres } \\
\text { con escopetas caza }\end{array}$ & $1894 / 10 / 00$ & Dave \\
\hline 200_S_156 & Lugares & Chateau de Dave & $1894 / 10 / 00$ & Dave \\
\hline 201_S_156 & Lugares & Chateau de Dave con lago & $1894 / 10 / 00$ & Dave \\
\hline $\begin{array}{l}\text { 202_S_15 } \\
7 \_1\end{array}$ & Personajes & $\begin{array}{l}\text { Dos niños sentados sobre } \\
\text { burro }\end{array}$ & $\begin{array}{l}1894 / 12 / 0 \\
0\end{array}$ & Madrid \\
\hline $203 \_S \_158$ & Personajes & $\begin{array}{l}\text { Alfonso montando a } \\
\text { "Godolfin" }\end{array}$ & $\begin{array}{l}1894 / 12 / 0 \\
0\end{array}$ & Madrid \\
\hline 204_S_158 & Personajes & $\begin{array}{l}\text { Alfonso montando a } \\
\text { "Godolfin" }\end{array}$ & $\begin{array}{l}1894 / 12 / 0 \\
0\end{array}$ & Madrid \\
\hline 205_S_159 & Lugares & $\begin{array}{l}\text { Canal de la Mancha. } \\
\text { Hombres y mujeres en barco }\end{array}$ & $\begin{array}{l}1894 / 09 / 0 \\
0\end{array}$ & Eastbourne \\
\hline 206_S_159 & Lugares & $\begin{array}{l}\text { Canal de la Mancha. Vista } \\
\text { del puerto }\end{array}$ & $\begin{array}{l}1894 / 09 / 0 \\
0 \\
\end{array}$ & Eastbourne \\
\hline 207_S_160 & Tauromaquia & Capea. Paseíllo de corto & & $\begin{array}{l}\text { Desconocid } \\
\mathrm{o}\end{array}$ \\
\hline 208_S_161 & Tauromaquia & Capea. Gradas & & $\begin{array}{l}\text { Desconocid } \\
\mathrm{o}\end{array}$ \\
\hline $\begin{array}{l}209 \_S \_162 \\
1\end{array}$ & Tauromaquia & Capea. Faena & & $\begin{array}{l}\text { Desconocid } \\
\mathrm{o}\end{array}$ \\
\hline
\end{tabular}




\begin{tabular}{|c|c|c|c|c|}
\hline $210 \_S \_163$ & Tauromaquia & Capea. Faena & & \begin{tabular}{|l} 
Desconocid \\
o
\end{tabular} \\
\hline 211_S_164 & Tauromaquia & Capea. Comienzo del paseíllo & & $\begin{array}{l}\text { Desconocid } \\
\mathrm{o}\end{array}$ \\
\hline 212_S_165 & Tauromaquia & $\begin{array}{l}\text { Capea. Hombre con muleta y } \\
\text { toro en primer plano }\end{array}$ & & $\begin{array}{l}\text { Desconocid } \\
\mathrm{o}\end{array}$ \\
\hline 213_S_166 & Animales & $\begin{array}{l}\text { Finca Flamenca. Burro del } \\
\text { agua }\end{array}$ & $\begin{array}{l}1894 / 02 / 0 \\
0\end{array}$ & Aranjuez \\
\hline 214_S_166 & Transporte & Finca Flamenca. Coches & $\begin{array}{l}1894 / 02 / 0 \\
0\end{array}$ & Aranjuez \\
\hline 215_S_167 & Casa Real & $\begin{array}{l}\text { Alfonso XIII en coche de } \\
\text { caballos }\end{array}$ & $\begin{array}{l}1894 / 03 / 0 \\
0\end{array}$ & Madrid \\
\hline 216_S_168 & Tauromaquia & $\begin{array}{l}\text { Plaza de toros. Suerte de } \\
\text { espadas }\end{array}$ & $\begin{array}{l}1894 / 05 / 3 \\
0\end{array}$ & Aranjuez \\
\hline 217_S_169 & Tauromaquia & Plaza de toros. Banderilleros & $\begin{array}{l}1894 / 05 / 3 \\
0\end{array}$ & Aranjuez \\
\hline $\begin{array}{l}218 \_S \_169 \\
2\end{array}$ & Tauromaquia & Plaza de toros. Picador caído & $\begin{array}{l}1894 / 05 / 3 \\
0\end{array}$ & Aranjuez \\
\hline $219 \_S \_170$ & Casa Real & $\begin{array}{l}\text { Jura de Alfonso XIII. Coches } \\
\text { de caballos }\end{array}$ & $\begin{array}{r}1902 / 05 / 2 \\
1 \\
\end{array}$ & Madrid \\
\hline $220 \_S \_170$ & Personajes & $\begin{array}{l}\text { El conde Valencia de Don } \\
\text { Juan y Cherry }\end{array}$ & $\begin{array}{r}1902 / 05 / 2 \\
1\end{array}$ & Madrid \\
\hline 221_S_171 & Casa Real & $\begin{array}{l}\text { Jura de Alfonso XIII. Coche } \\
\text { de las Infantas }\end{array}$ & $\begin{array}{r}1902 / 05 / 2 \\
1 \\
\end{array}$ & Madrid \\
\hline $222 \_S \_172$ & Casa Real & $\begin{array}{l}\text { Jura de Alfonso XIII. Guardia } \\
\text { Real en desfile }\end{array}$ & $\begin{array}{r}1902 / 05 / 2 \\
1 \\
\end{array}$ & Madrid \\
\hline 223_S_173 & Casa Real & Jura de Alfonso XIII. Desfile & $\begin{array}{r}1902 / 05 / 2 \\
1 \\
\end{array}$ & Madrid \\
\hline 224_S_174 & Casa Real & $\begin{array}{l}\text { Jura de Alfonso XIII. Coche } \\
\text { del Duque Vladimiro }\end{array}$ & $\begin{array}{r}1902 / 05 / 2 \\
1\end{array}$ & Madrid \\
\hline 225_S_175 & Casa Real & $\begin{array}{l}\text { Jura de Alfonso XIII. } \\
\text { Comitiva Real }\end{array}$ & $\begin{array}{r}1902 / 05 / 1 \\
7\end{array}$ & Madrid \\
\hline 226_S_176 & Casa Real & $\begin{array}{l}\text { Jura de Alfonso XIII. Duques } \\
\text { Counaupht y Alba }\end{array}$ & $\begin{array}{l}1902 / 05 / 1 \\
7\end{array}$ & Madrid \\
\hline $\begin{array}{l}227 \_S \_177 \\
1\end{array}$ & Casa Real & $\begin{array}{l}\text { Jura de Alfonso XIII. Coche } \\
\text { de caballos }\end{array}$ & $\begin{array}{l}1902 / 05 / 1 \\
7\end{array}$ & Madrid \\
\hline $228 \_S \_178$ & Casa Real & $\begin{array}{l}\text { Jura de Alfonso XIII. Coche } \\
\text { de caballos }\end{array}$ & $\begin{array}{l}1902 / 05 / 1 \\
7\end{array}$ & Madrid \\
\hline 229_S_179 & Casa Real & $\begin{array}{l}\text { Jura de Alfonso XIII. Coche } \\
\text { de caballos }\end{array}$ & $\begin{array}{l}1902 / 05 / 1 \\
7\end{array}$ & Madrid \\
\hline 230_S_180 & Casa Real & $\begin{array}{l}\text { Jura de Alfonso XIII. Coche } \\
\text { de caballos }\end{array}$ & $\begin{array}{l}1902 / 05 / 1 \\
7\end{array}$ & Madrid \\
\hline
\end{tabular}




\begin{tabular}{|c|c|c|c|c|}
\hline 231_S_181 & Casa Real & $\begin{array}{l}\text { Jura de Alfonso XIII. Coche } \\
\text { de caballos }\end{array}$ & $\begin{array}{l}1902 / 05 / 1 \\
7\end{array}$ & Madrid \\
\hline$\overline{2} 232 \_S \_182$ & Casa Real & $\begin{array}{l}\text { Jura de Alfonso XIII. Coche } \\
\text { de caballos }\end{array}$ & $\begin{array}{l}1902 / 05 / 1 \\
7\end{array}$ & Madrid \\
\hline $233 \_\mathrm{S} \_183$ & Casa Real & $\begin{array}{l}\text { Jura de Alfonso XIII. Coche } \\
\text { de caballos }\end{array}$ & $\begin{array}{l}1902 / 05 / 1 \\
7\end{array}$ & Madrid \\
\hline 234_S_184 & Casa Real & $\begin{array}{l}\text { Jura de Alfonso XIII. Coche } \\
\text { de caballos }\end{array}$ & $\begin{array}{l}1902 / 05 / 1 \\
7\end{array}$ & Madrid \\
\hline $235 \_S \_185$ & Personajes & $\begin{array}{l}\text { Dos hombres sentados en } \\
\text { roca y uno de pie }\end{array}$ & $\begin{array}{l}1898 / 00 / 0 \\
0\end{array}$ & $\begin{array}{l}\text { Saint } \\
\text { Moritz }\end{array}$ \\
\hline 236_S_186 & Personajes & $\begin{array}{l}\text { Siete hombres y dos mujeres } \\
\text { en día de campo }\end{array}$ & $\begin{array}{l}1898 / 00 / 0 \\
0\end{array}$ & $\begin{array}{l}\text { Saint } \\
\text { Moritz }\end{array}$ \\
\hline $\begin{array}{l}237 \_S \_186 \\
2\end{array}$ & Personajes & $\begin{array}{l}\text { Dos hombres sentados en } \\
\text { roca }\end{array}$ & $\begin{array}{l}1898 / 00 / 0 \\
0\end{array}$ & $\begin{array}{l}\text { Saint } \\
\text { Moritz }\end{array}$ \\
\hline $238 \_\mathrm{S} \_187$ & Personajes & $\begin{array}{l}\text { Grupo de hombres y mujeres } \\
\text { en día de campo }\end{array}$ & $\begin{array}{l}1898 / 00 / 0 \\
0\end{array}$ & $\begin{array}{l}\text { Saint } \\
\text { Moritz }\end{array}$ \\
\hline $\begin{array}{c}239 \_S \_187 \\
2\end{array}$ & Personajes & $\begin{array}{l}\text { Grupo de hombres y mujeres } \\
\text { en día de campo }\end{array}$ & $\begin{array}{l}1898 / 00 / 0 \\
0\end{array}$ & $\begin{array}{l}\text { Saint } \\
\text { Moritz }\end{array}$ \\
\hline $\begin{array}{l}240 \_S \_188 \\
1\end{array}$ & Personajes & $\begin{array}{l}\text { Palacio. Interior. Cuatro } \\
\text { hombres y dos mujeres }\end{array}$ & $\begin{array}{l}1898 / 00 / 0 \\
0\end{array}$ & La Granja \\
\hline 241_S_188 & Lugares & Palacio & $\begin{array}{l}1898 / 00 / 0 \\
0\end{array}$ & La Granja \\
\hline $\begin{array}{l}242 \_S \_189 \\
1\end{array}$ & Personajes & $\begin{array}{l}\text { Hombres paseando entre } \\
\text { jardines }\end{array}$ & $\begin{array}{l}1898 / 00 / 0 \\
0\end{array}$ & La Granja \\
\hline $\begin{array}{l}243 \_S \_189 \\
2\end{array}$ & Lugares & Fuente de los jardines & $\begin{array}{l}1898 / 00 / 0 \\
0\end{array}$ & La Granja \\
\hline 244_S_190 & Lugares & Fuente de los jardines & $\begin{array}{l}1898 / 00 / 0 \\
0\end{array}$ & La Granja \\
\hline 245_S_191 & Deporte & Partido de polo & $\begin{array}{l}1898 / 00 / 0 \\
0\end{array}$ & \\
\hline $\begin{array}{l}\overline{2} 46 \_S \_192 \\
1\end{array}$ & Lugares & $\begin{array}{l}\text { Vista de río con dos caballos } \\
\text { y montañas al fondo }\end{array}$ & $\begin{array}{l}1898 / 00 / 0 \\
0\end{array}$ & Zuazo \\
\hline $\begin{array}{l}247 \_S \_192 \\
2\end{array}$ & Lugares & Puente de piedra & $\begin{array}{l}1898 / 00 / 0 \\
0\end{array}$ & Zuazo \\
\hline 248_S_193 & Lugares & Calle. Al fondo el Acueducto & $\begin{array}{l}1898 / 00 / 0 \\
0\end{array}$ & Segovia \\
\hline $\begin{array}{l}249 \_S \_193 \\
2\end{array}$ & Lugares & Acueducto & $\begin{array}{l}1898 / 00 / 0 \\
0\end{array}$ & Segovia \\
\hline 250_S_194 & Lugares & $\begin{array}{l}\text { Palacio de las Dueñas. Patio } \\
\text { interior }\end{array}$ & $\begin{array}{l}1898 / 00 / 0 \\
0\end{array}$ & Sevilla \\
\hline $\begin{array}{l}\overline{2} \text { 251_S_194 } \\
2\end{array}$ & Lugares & $\begin{array}{l}\text { Palacio de las Dueñas. Patio } \\
\text { interior }\end{array}$ & $\begin{array}{l}1898 / 00 / 0 \\
0\end{array}$ & Sevilla \\
\hline
\end{tabular}




\begin{tabular}{|c|c|c|c|c|}
\hline $252 \_S \_195$ & Lugares & Río Guadalquivir & $\begin{array}{l}1898 / 00 / 0 \\
0\end{array}$ & Sevilla \\
\hline $\begin{array}{c}253 \_S \_195 \\
2\end{array}$ & Lugares & $\begin{array}{l}\text { Río Guadalquivir. Torre del } \\
\text { Oro }\end{array}$ & $\begin{array}{l}1898 / 00 / 0 \\
0\end{array}$ & Sevilla \\
\hline $\begin{array}{l}254 \_S \_196 \\
1\end{array}$ & Lugares & Río Guadalquivir. Velero & $\begin{array}{l}1898 / 00 / 0 \\
0\end{array}$ & Sevilla \\
\hline 255_S_196 & Lugares & Río Guadalquivir & $\begin{array}{l}1898 / 00 / 0 \\
0\end{array}$ & Sevilla \\
\hline 256_S_197 & Lugares & Río Guadalquivir. Barco & $\begin{array}{l}1898 / 00 / 0 \\
0\end{array}$ & Sevilla \\
\hline 257_S_197 & Lugares & $\begin{array}{l}\text { Río Guadalquivir. Velero y } \\
\text { barca }\end{array}$ & $\begin{array}{l}1898 / 00 / 0 \\
0\end{array}$ & Sevilla \\
\hline $\begin{array}{c}\overline{2} 58 \_S \_198 \\
1\end{array}$ & Lugares & Río Guadalquivir & $\begin{array}{l}1898 / 00 / 0 \\
0\end{array}$ & Sevilla \\
\hline $\begin{array}{c}259 \_S \_198 \\
2\end{array}$ & Lugares & Río Guadalquivir & $\begin{array}{l}1898 / 00 / 0 \\
0\end{array}$ & Sevilla \\
\hline $\begin{array}{l}260 \_S \_199 \\
1\end{array}$ & Personajes & $\begin{array}{l}\text { Cinco hombres y una mujer. } \\
\text { Caballo en patio }\end{array}$ & $\begin{array}{l}1895 / 05 / 0 \\
1\end{array}$ & Aranjuez \\
\hline 261_S_200 & Animales & Jaca "Predilecta" & $\begin{array}{l}1895 / 05 / 0 \\
1\end{array}$ & Aranjuez \\
\hline $262 \_S \_200$ & Animales & Jaca "Predilecta" & $\begin{array}{l}1895 / 05 / 0 \\
1\end{array}$ & Aranjuez \\
\hline 263_S_201 & Personajes & $\begin{array}{l}\text { Palacio. Jardín del Príncipe. } \\
\text { Personas posando }\end{array}$ & $\begin{array}{l}1895 / 05 / 0 \\
1\end{array}$ & Aranjuez \\
\hline $\begin{array}{l}264 \_S \_202 \\
1\end{array}$ & Animales & $\begin{array}{l}\text { Caballo en patio de casa con } \\
\text { mozo }\end{array}$ & $\begin{array}{l}1895 / 05 / 0 \\
1\end{array}$ & Aranjuez \\
\hline 265_S_203 & Lugares & Jardines & $\begin{array}{l}1895 / 05 / 0 \\
1\end{array}$ & Aranjuez \\
\hline $\begin{array}{l}266 \_S \_204 \\
1\end{array}$ & Personajes & $\begin{array}{l}\text { Finca Romanillos. Hombres a } \\
\text { caballo }\end{array}$ & $\begin{array}{l}1895 / 05 / 0 \\
0\end{array}$ & Boadilla \\
\hline 267_S_204 & Personajes & $\begin{array}{l}\text { Finca Romanillos. Hombres a } \\
\text { caballo }\end{array}$ & $\begin{array}{l}1895 / 05 / 0 \\
0\end{array}$ & Boadilla \\
\hline $\begin{array}{l}269 \_S \_205 \\
2\end{array}$ & Personajes & $\begin{array}{l}\text { Finca Romanillos. Hombres } \\
\text { subidos en un árbol }\end{array}$ & $\begin{array}{l}1895 / 05 / 0 \\
0\end{array}$ & Boadilla \\
\hline 270_S_206 & Personajes & $\begin{array}{l}\text { Finca Romanillos. Hombres a } \\
\text { caballo }\end{array}$ & $\begin{array}{l}1895 / 05 / 0 \\
0\end{array}$ & Boadilla \\
\hline $\begin{array}{l}271 \_S \_207 \\
1\end{array}$ & Personajes & $\begin{array}{l}\text { Finca Romanillos. Hombres y } \\
\text { mujer en burro }\end{array}$ & $\begin{array}{l}1895 / 05 / 0 \\
0\end{array}$ & Boadilla \\
\hline 272_S_208 & Personajes & $\begin{array}{l}\text { Finca Flamenca. Hombres } \\
\text { sujetando dos perros }\end{array}$ & $\begin{array}{l}1895 / 04 / 0 \\
0\end{array}$ & Aranjuez \\
\hline $\begin{array}{l}273 \_S \_209 \\
1\end{array}$ & Lugares & $\begin{array}{l}\text { Finca Flamenca. Vista del } \\
\text { lago }\end{array}$ & $\begin{array}{l}1895 / 03 / 0 \\
0\end{array}$ & Aranjuez \\
\hline
\end{tabular}




\begin{tabular}{|c|c|c|c|c|}
\hline 274_S_210 & Caza & $\begin{array}{l}\text { Finca Flamenca. Hombres y } \\
\text { mujeres de caza }\end{array}$ & \begin{tabular}{|l}
$1895 / 02 / 0$ \\
0 \\
\end{tabular} & Aranjuez \\
\hline $275 \_S \_210$ & Caza & $\begin{array}{l}\text { Finca Flamenca. Hombres y } \\
\text { mujeres de caza }\end{array}$ & $\begin{array}{l}1895 / 02 / 0 \\
0\end{array}$ & Aranjuez \\
\hline $\begin{array}{l}276 \_S \_21 \\
1 \_1\end{array}$ & Caza & $\begin{array}{l}\text { Finca Flamenca. Hombres y } \\
\text { mujeres de caza }\end{array}$ & $\begin{array}{l}1895 / 02 / 0 \\
0\end{array}$ & Aranjuez \\
\hline
\end{tabular}




\section{Anexo 2. Fotografías}

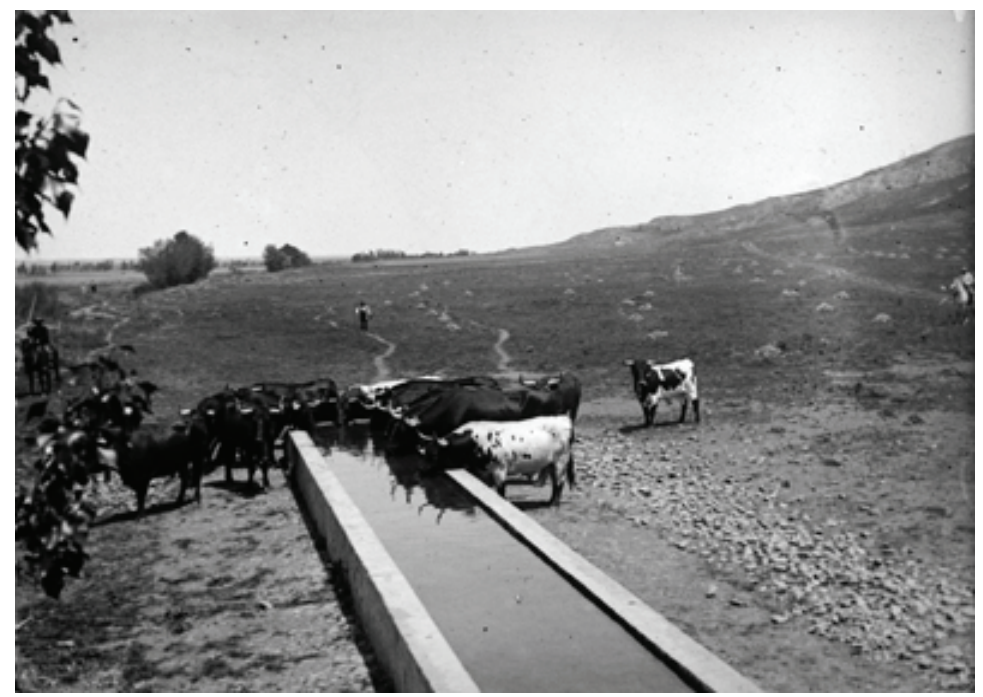

Figura 12. Alcalá de Henares. Toros en el campo. Soto de la ciudad, 1894

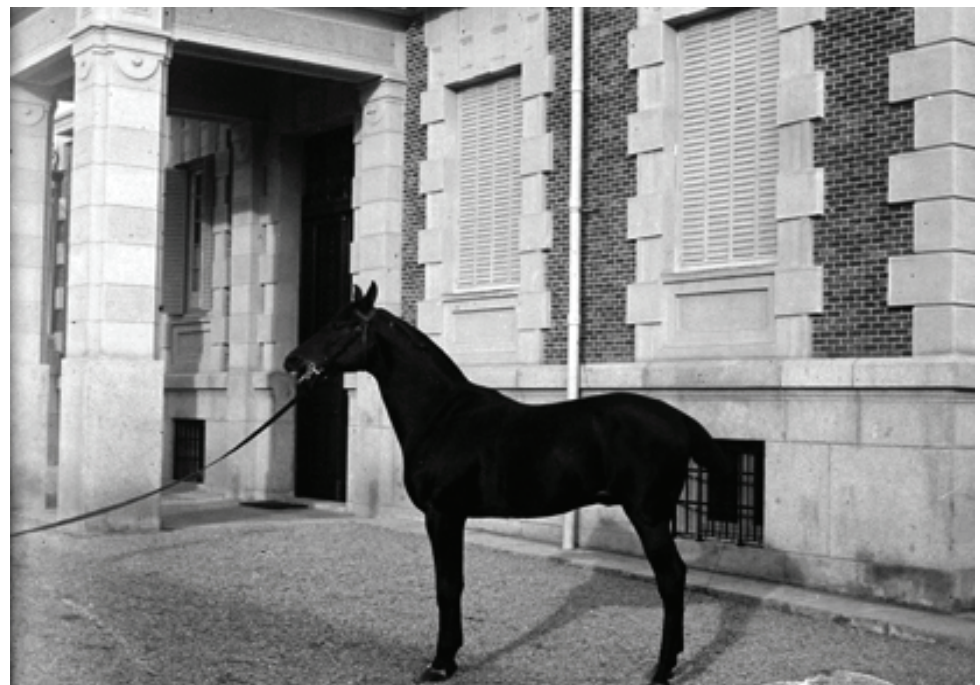

Figura 13. El caballo Sarah, propiedad de la familia Torre-Arias, 1895 


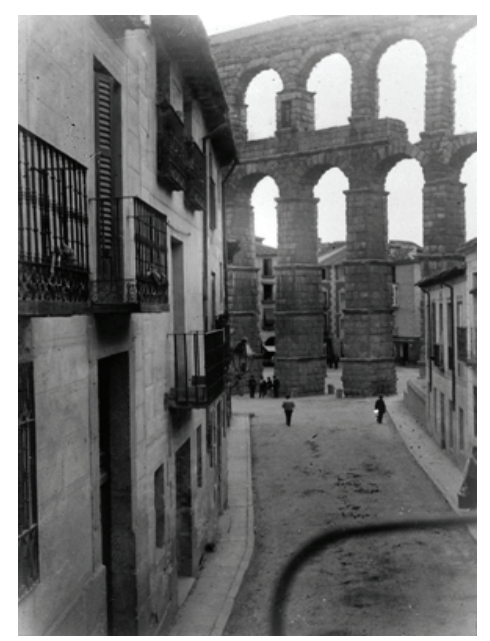

Figura 14. Segovia. Acueducto,

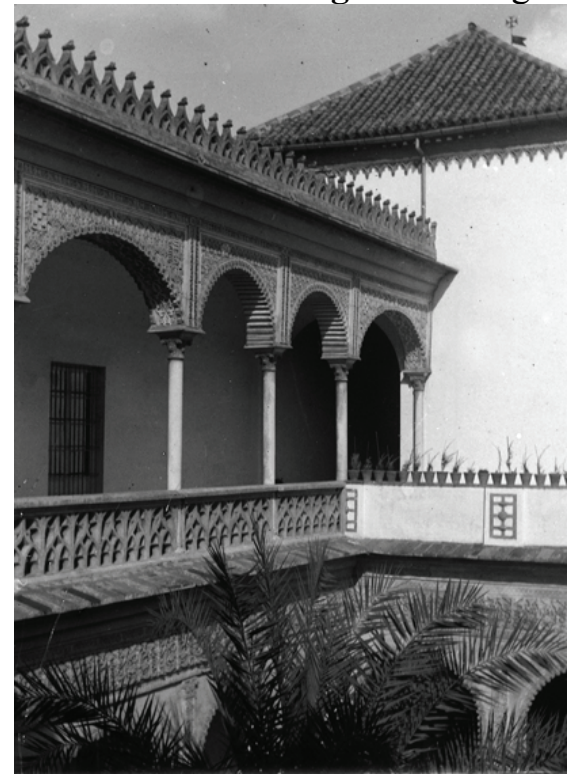

Figura 15. Sevilla. Palacio de las Dueñas, 1898. 


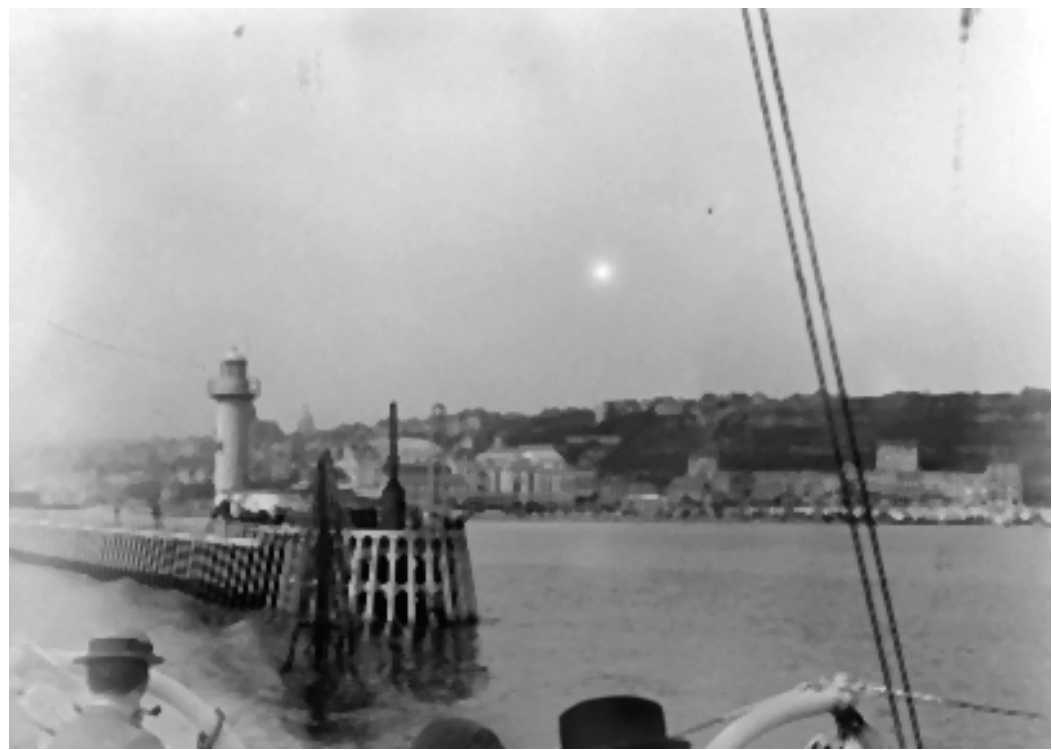

Figura 16. Eastbourne. Canal de la Mancha. Vista del puerto, 1893

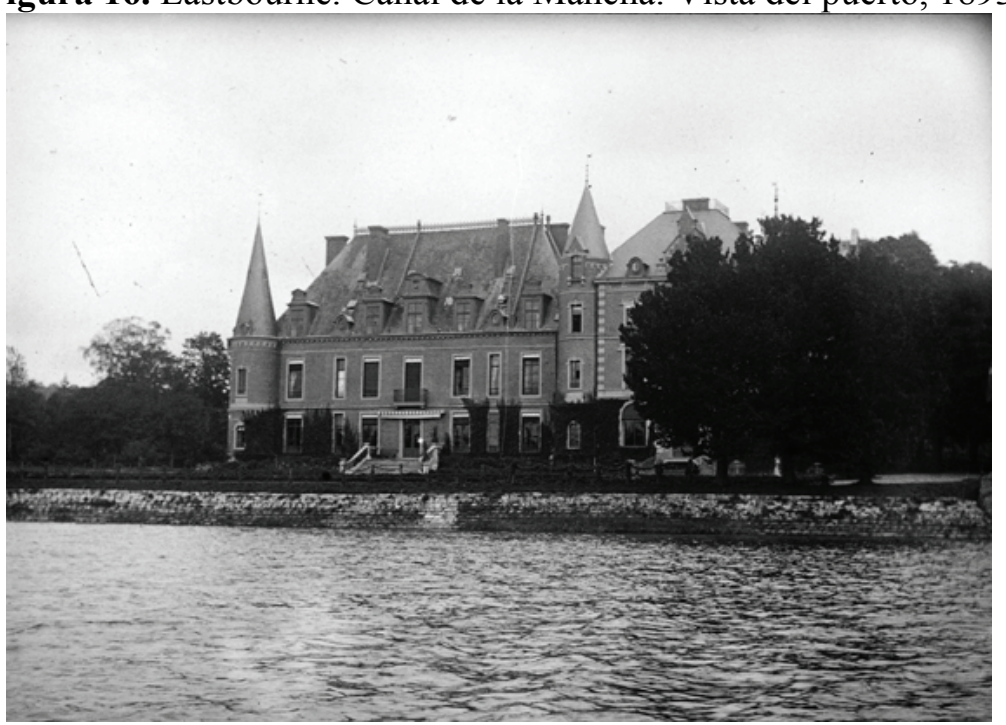

Figura 17. Dave. Vista del castillo y el lago, 1894 


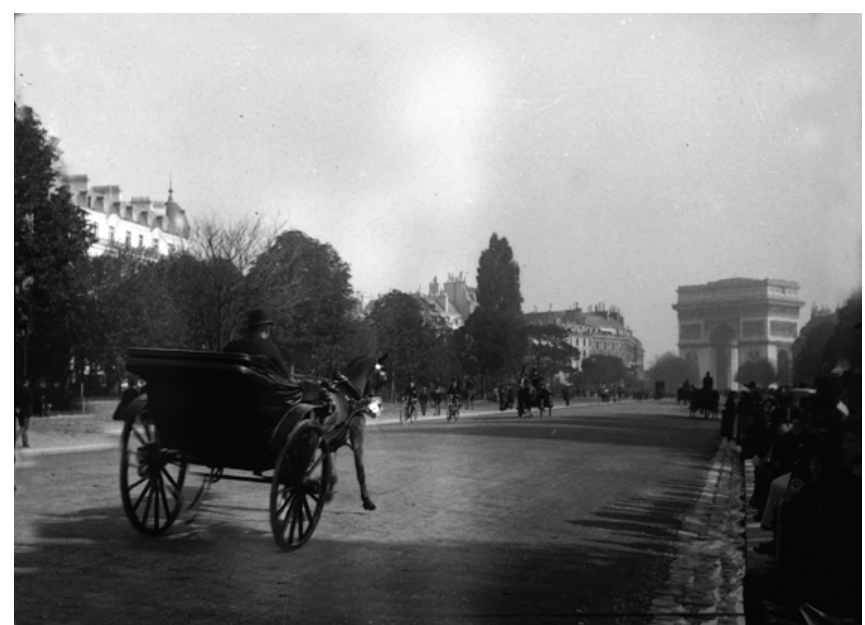

Figura 18. París. Paseo del Bosque de Bologne, 1893 


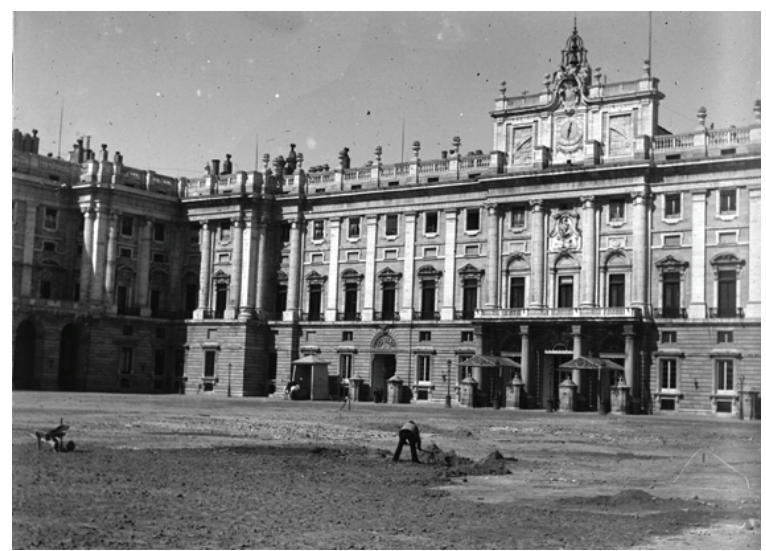

Figura 19. Madrid. Palacio Real, 1894

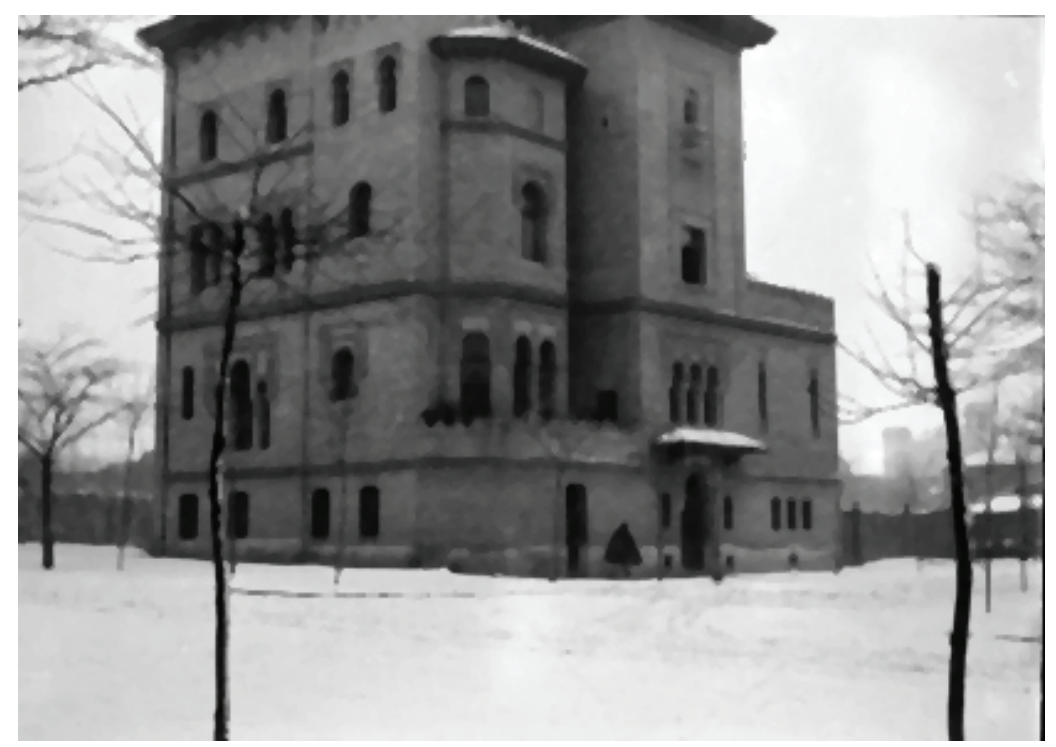

Figura 20. Madrid. Instituto Valencia de Don Juan en la calle Fortuny nevada, 1894 


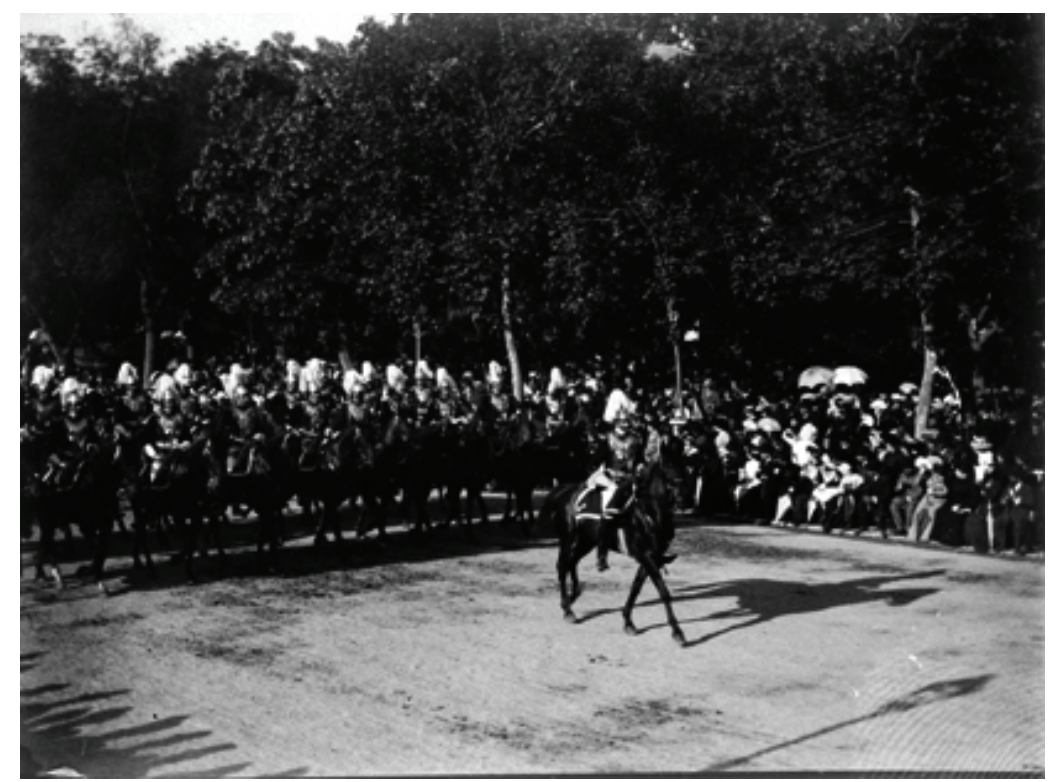

Figura 21. Madrid. Jura del Rey. Desfile de la Guardia Real, 21 de mayo de 1902

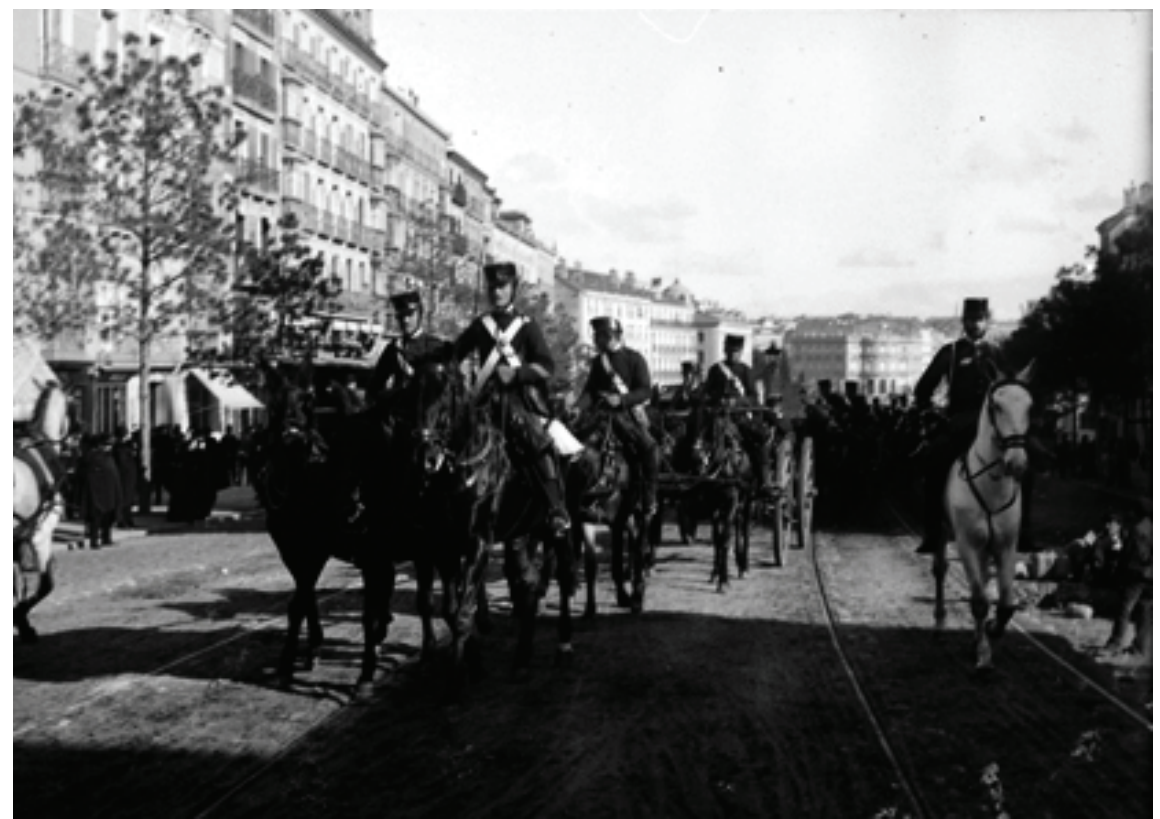

Figura 22. Madrid. Grupo de artilleros en la calle de Alcalá, 1893 


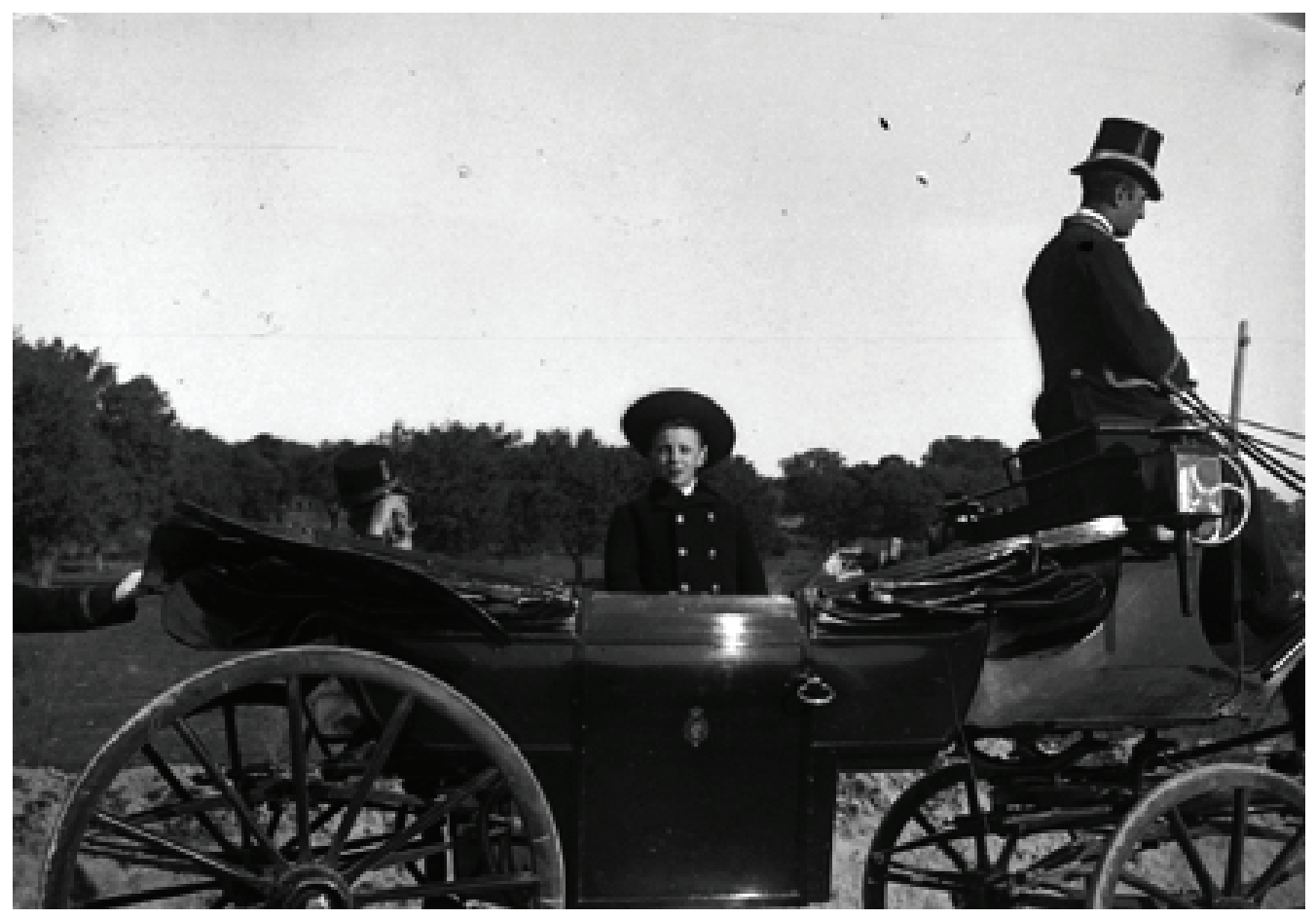

Figura 23. Alfonso XIII niño, marzo de 1894

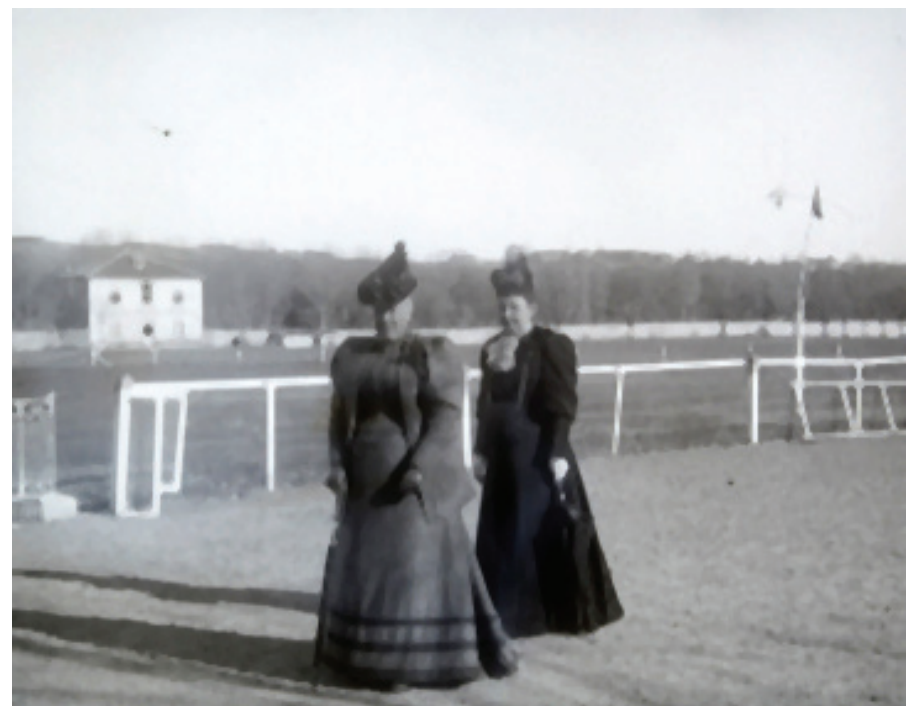

Figura 24. Isabel de Borbón en el hipódromo de Madrid, marzo de 1894 